\title{
Chemistry-transport modeling of the satellite observed distribution of tropical tropospheric ozone
}

\author{
W. Peters ${ }^{1}$, M. Krol ${ }^{1}$, F. Dentener ${ }^{2}$, A. M. Thompson ${ }^{3}$, and J. Lelieveld ${ }^{4}$ \\ ${ }^{1}$ Institute for Marine and Atmospheric Research Utrecht, Utrecht, Netherlands \\ ${ }^{2}$ Joint Research Centre, Ispra, Italy \\ ${ }^{3}$ Goddard Space Flight Center, NASA, Maryland, USA \\ ${ }^{4}$ Max Planck Institut für Chemie, Mainz, Germany \\ Received: 2 October 2001 - Published in Atmos. Chem. Phys. Discuss.: 3 December 2001 \\ Revised: 8 April 2002 - Accepted: 19 April 2002 - Published: 30 May 2002
}

\begin{abstract}
We have compared the 14-year record of satellite derived tropical tropospheric ozone columns (TTOC) from the NIMBUS-7 Total Ozone Mapping Spectrometer (TOMS) to TTOC calculated by a chemistry-transport model (CTM). An objective measure of error, based on the zonal distribution of TTOC in the tropics, is applied to perform this comparison systematically. In addition, the sensitivity of the model to several key processes in the tropics is quantified to select directions for future improvements. The comparisons indicate a widespread, systematic (20\%) discrepancy over the tropical Atlantic Ocean, which maximizes during austral Spring. Although independent evidence from ozonesondes shows that some of the disagreement is due to satellite overestimate of TTOC, the Atlantic mismatch is largely due to a misrepresentation of seasonally recurring processes in the model. Only minor differences between the model and observations over the Pacific occur, mostly due to interannual variability not captured by the model. Although chemical processes determine the TTOC extent, dynamical processes dominate the TTOC distribution, as the use of actual meteorology pertaining to the year of observations always leads to a better agreement with TTOC observations than using a random year or a climatology. The modeled TTOC is remarkably insensitive to many model parameters due to efficient feedbacks in the ozone budget. Nevertheless, the simulations would profit from an improved biomass burning calendar, as well as from an increase in $\mathrm{NO}_{\mathrm{x}}$ abundances in free tropospheric biomass burning plumes. The model showed the largest response to lightning $\mathrm{NO}_{\mathrm{x}}$ emissions, but systematic improvements could not be found. The use of multi-year satellite derived tropospheric data to systematically test and improve a CTM is a promising new addition to existing methods of model validation, and is a
\end{abstract}

Correspondence to: W. Peters (W.Peters@ phys.uu.nl) first step to integrating tropospheric satellite observations into global ozone modeling studies. Conversely, the CTM may suggest improvements to evolving satellite retrievals for tropospheric ozone.

\section{Introduction}

The availability of trace gas measurements in the tropics has increased considerably by a large number of intensive campaigns (LBA, PEM, TRACE, INDOEX, SAFARI) and the expansion of the number of measurement stations in the tropics. The interest in the tropics is based on the active photochemistry, rapid convective mixing along with lightning discharge, high humidity, widespread biomass burning, and growing industrial emissions. All these processes influence the concentration of oxidants such as ozone and the hydroxyl radical. The latter plays a crucial role in the removal of biogenic emissions and anthropogenic pollution from the atmosphere.

Observations from satellites play an increasingly important role in monitoring of the chemical composition of the troposphere. The Total Ozone Mapping Spectrometer (TOMS) instrument aboard the NIMBUS-7 and Earth Probe (EP) Satellites (McPeters and Labow, 1996) has been used to retrieve tropospheric column ozone (TTOC) (Fishman and Larsen, 1987; Kim et al., 1996; Ziemke et al., 1998; Hudson and Thompson, 1998), while the GOME instrument aboard ERS-2 has been used to retrieve columns of tropospheric $\mathrm{NO}_{2}, \mathrm{SO}_{2}$ (Eisinger and Burrows, 1998; Burrows et al., 1999), and BrO (Richter et al., 1998). In the near future, SCIAMACHY (Burrows and Chance, 1992) will expand this suite of trace gases with $\mathrm{N}_{2} \mathrm{O}, \mathrm{CO}_{2}, \mathrm{CO}$ and $\mathrm{CH}_{4}$. These last 
two trace gases are also the focal point of the MOPITT instrument (Pan et al., 1998) aboard the EOS-TERRA satellite, launched in 2000. The most important advantages of satellite observations are the global coverage and the continuous monitoring on time scales from days to years, and sometimes even decades. For historically data sparse regions such as the tropics, this will contribute significantly to our understanding of atmospheric processes and help detect changes.

In addition, satellite measurements can easily be combined with chemistry-transport models (CTM) and global circulation models (GCM), since spatial and temporal scales are often comparable. There are several ways in which these properties can be exploited in a quantitative way. This includes for instance assimilation of satellite measurements into models to constrain chemistry calculations (e.g. Jeuken et al., 1999) and provide boundary conditions. Also, satellite measurements can be used as additional constraints in inversion problems, where the global distribution of a tracer is used to infer the distribution and magnitude of its sources and sinks (e.g. Houweling et al., 1999). Vice versa, model calculations can be used in satellite retrieval algorithms to provide a "first guess" field or to provide missing parameters needed in the retrieval (e.g. Chance et al., 2000). The growing amount of satellite observations and expansion of remotely sensed trace species will intensify the use of these observations in modeling studies.

From the several tropospheric satellite observations available at the moment, the TTOC record derived from the NIMBUS-7 observations is the most extensive. It spans the complete NIMBUS-7 observational period (1979-1992) on a high spatial $(2 \times 1$ degrees) and temporal (twice monthly) resolution. This has enabled analysis of seasonal cycles (Martin et al., 2000), trends (Thompson and Hudson, 1999) and interannual variability (Ziemke et al., 1999) in tropical ozone. Moreover, this dataset has shown to be very useful in studying both local scale features such as the effect of El Niño-Southern Oscillation (ENSO) related fires over Indonesia (Chandra et al., 1998; Thompson et al., 2001), as well as large scale phenomena such as the evolution of the South Atlantic ozone maximum (Thompson and Hudson, 1999) and the changing Walker circulation during ENSO (Ziemke et al., 1999). Neverthless, most modeling studies have only used the TTOC data for a qualitative comparison, while ozone sondes (Logan, 1999)) were used for a quantitative comparison. Here, we explore how satellite derived TTOC can be used to validate and improve our CTM.

Previously, we have tested our model against in situ data from sondes and ground-based stations (Lelieveld and Dentener, 2000; Marufu et al., 2000; Peters et al., 2001). Comparison to the climatology of Logan (1999) revealed an apparent problem in the representation of the zonal ozone distribution in the tropics, which shows a maximum of TTOC over the Atlantic Ocean and a minimum over the Pacific Ocean. This distribution is often called the "zonal wave one pattern" (Kim et al., 1996), and is a typical example of a large scale feature in tropical ozone that can be well studied with a combination of global models and satellite observations. Therefore, we present a quantitative comparison with TTOC derived with the Modified Residual (MR) algorithm of Hudson and Thompson (1998). We have developed a measure of error to consistently perform this comparison. This measure of error allows us to recognize systematic shortcomings in our model on seasonal and interannual time scales, and study the influence of meteorology and photochemistry on our model results. Moreover, it helps to identify processes that should be considered for improvement and allows us to quantify the sensitivity of our model results to several processes such as biomass burning and lightning $\mathrm{NO}_{\mathrm{x}}$ emissions. It is important to stress that these techniques are not used to "tune" the model to observations. The processes that are most likely to cause the observed differences should be carefully studied in future work, preferably in a three dimensional perspective using ozone sondes. Our work presented in Sect. 8 should be seen as an exploration of model sensitivities providing guidance to actual improvements.

We start in Sect. 2 with an introduction of the CTM that was used in this study, and a discussion of the photochemistry, biomass burning and lightning $\mathrm{NO}_{\mathrm{x}}$ emissions. Next, we give some basic information on the TTOC data used (Sect. 3). In order to compare model and measurements, we introduce a measure of error in Sect. 4, which will be the basis for the results in this paper. We apply this measure of error to firstly identify the magnitude, location, and seasonality of the discrepancy between model and data (Sect. 5, after which we will look at the roles of meteorology (Sect. 6) and photochemistry (Sect. 7) in our model. The latter is done by looking at the spatial and temporal distribution of photochemically marked ozone tracers. The processes that are identified as most likely candidates to explain the discrepancy are further studied in Sect. 8, through a series of sensitivity experiments in which changes in emission magnitude and distributions are applied. The results from these experiments are illustrated with several ozone sondes in Sect. 9. Finally, we discuss our results in Sect. 10, and give a short summary in Sect. 11.

\section{Model Description}

We use the chemical tracer transport model version 3 (TM3) to simulate transport and photochemistry of 48 trace gases within a global domain. The TM3 model has a horizontal resolution of $5^{\circ}$ longitude $\times 3.75^{\circ}$ latitude and uses 19 layers with a hybrid of sigma-pressure coordinates in the verti$\mathrm{cal}$, with the model top at $10 \mathrm{~Pa}$. Approximately five layers constitute the boundary layer, nine the free troposphere, and five the lower and middle stratosphere. Transport in the offline model is prescribed using ECMWF data (Gibson et al., 1997). 
Table 1. Processes included in the model and references to the original work

\begin{tabular}{|c|c|c|}
\hline Process & Based on & Ref. $^{a}$ \\
\hline Advection & Russel and Lerner (1981) & Dentener et al. (1999) \\
\hline Convection (subgrid) & Tiedtke (1989) & Dentener et al. (1999) \\
\hline Turbulent mixing (subgrid) & Louis (1979) & Dentener et al. (1999) \\
\hline Stratospheric boundary & & Lelieveld and Dentener (2000) \\
\hline \multirow[t]{2}{*}{ Photolysis } & Landgraf and Crutzen (1998) & \\
\hline & Krol and van Weele (1997) & \\
\hline Dry deposition & Wesely (1989) & Ganzeveld et al. (1998) \\
\hline Wet deposition & Guelle et al. (1998) & Jeuken (2000) \\
\hline Biomass burning emissions $b$ & Hao and Liu (1994) & Marufu et al. (2000) \\
\hline \multirow[t]{2}{*}{ Lightning $\mathrm{NO}_{\mathrm{x}}$ emissions ${ }^{b}$} & Price and Rind (1992) & \\
\hline & Levy et al. (1996) & Meijer et al. (2001) \\
\hline Other emissions & Olivier et al. (1996) & Lelieveld and Dentener (2000) \\
\hline \multirow[t]{2}{*}{ Chemistry, CBM-IV ${ }^{b}$} & Gery et al. (1989) & \\
\hline & Houweling et al. (1998) & Houweling et al. (1998) \\
\hline
\end{tabular}

The model uses six-hourly, 3-dimensional fields of geopotential height, horizontal mass-fluxes, temperature, specific humidity and cloud information (liquid water and ice water content), as well as 2D information on cloud cover and precipitation (large-scale and convective). The subgrid scale transport by turbulence and convection is calculated from archived diffusion and entrainment/detrainment coefficients from the ECMWF model using a modified scheme by Louis (1979) and Tiedtke (1989) scheme respectively.

All the input fields are extrapolated from the ECMWF archived resolution (spectral, T106) to the TM3 model resolution. The results presented in Sect. 5 and 6 were obtained using the multi-year (1979-1993) simulation by Lelieveld and Dentener (2000), which was also used in Peters et al. (2001). The configuration of the TM3 model in the sensitivity studies (Sect. 8) is identical, and pertain to the year 1992. However, the model currently runs on a new SGI-3800 massive parallel system from the Dutch National Supercomputing Facility (NCF). A short list of processes in the model and references to more elaborate discussion of these processes is given in Table 1. We will limit ourselves to a description of the processes explicitly relevant for this study, being the emissions from biomass burning, the photochemistry of ozone and its precursors, and the lightning $\mathrm{NO}_{\mathrm{x}}$ parameterization.

\subsection{Biomass burning emissions}

The emissions of biomass burning in the model were originally constructed from two datasets. The EDGAR emission database (Olivier et al., 1996) prescribes the total amount of
$\mathrm{CO}, \mathrm{HCHO}, \mathrm{NO}_{\mathrm{x}}$, and $\mathrm{NMHC}$ emitted yearly from anthropogenic and natural sources. This database is based on estimates for the year 1990 that were obtained from various sources on a resolution of $1^{\circ}$ longitude $\times 1^{\circ}$ latitude. For the temporal distribution of these emissions, the model relies on the Hao and Liu (1994) fire calendar, which contains monthly fractions of annual amounts of biomass burned on a $5^{\circ}$ longitude $\times 5^{\circ}$ latitude resolution. For the sensitivity studies presented in Sect. 8, we have replaced the fire calendar of Hao and Liu (1994) with one based on fire counts from the AVHRR satellite (Dwyer et al., 1999), which contains 10-day composites of global fire activity for 1992-1993. The observations were used to construct a time distribution function for each gridbox, by scaling the monthly total of counts by the yearly total of counts, yielding a fraction of fires occurring each month. Thus, the yearly totals remain the same, but the emissions maximize in the month with the largest number of fires.

It is important to note that this approach is meant to provide a simple alternative to the use of the Hao and Liu (1994) database, suitable for a model sensitivity analysis. In our algorithm, we do not account for the size of the fires that were observed; large fires and small fires contribute equally to our calendar, while in reality the amount of trace gases released to the atmosphere can differ strongly. Our algorithm will therefore overestimate the influence of these small fires and, since the total emissions are constant, underestimate the influence of large fires. Also, our algorithm does not include the smoldering phase of the fires, which can continue for several weeks especially after forest fires [M. O. Andreae and P. Merlet: Emission of trace gases and aerosols from 
biomass burning, Global Biogeochemical Cycles, accepted, 2000]. Due to the neglect of the smoldering phase, the timing of smoldering-related emissions (such as $\mathrm{CO}, \mathrm{NH}_{3}$ ) is biased towards the moment of detection of the fire, i.e. the flaming phase. Nevertheless, our alternative fire calendar suffices for a sensitivity analysis, whereas real satellite derived emission estimates require a more sophisticated approach (Pinty et al., 2000) [B. Duncan, R. Martin, A. Staudt, R. Yevich and J. Logan: Interannual and Seasonal Variability of Biomass Burning Emissions Constrained by Remote-Sensed Observations, manuscript in preparation, 2001].

\subsection{Photochemistry of ozone}

Photochemistry in the TM3 model is based on the CBM-4 mechanism of Gery et al. (1989). It includes 38 trace gases and 110 gas phase reactions. The CBM-4 mechanism was initially intended to simulate ozone photochemistry over urban areas with high $\mathrm{NO}_{\mathrm{x}}$ abundances. Therefore, Houweling et al. (1998) modified the scheme such that low $\mathrm{NO}_{\mathrm{x}}$ conditions are better represented. This has improved ozone photochemistry over more remote areas, where $\mathrm{NO}_{\mathrm{x}}$ concentrations are much lower. To reduce the number of reactions and species, the CBM-4 mechanism uses a form of structural lumping, where trace gases of common origin with similar structures, lifetimes and reactive properties are treated as one species, which has the common characteristics of all the species it is meant to represent. This concept and the consequences for the photochemistry are described in more detail in the work of Gery et al. (1989), Duncan and Chameides (1998), Houweling et al. (1998) and Pöschl et al. (2000).

Precursors for ozone production that are emitted from biomass burning include $\mathrm{NO}_{\mathrm{x}}, \mathrm{CO}$, formaldehyde and acetaldehyde. Other NMHC compounds that are known to originate from biomass burning (e.g. acetone, acetonitrile, ethene) are represented through the emissions of several lumped species (parafinic and olefinic NMHC's, methylglyoxal). The scheme includes the photochemistry of peroxyacetyl nitrate (PAN), which is an important secondary product from the oxidation of acetaldehyde and contributes significantly to the free tropospheric nitrogen budget (Singh et al., 1995). Dry deposition is an important sink for $\mathrm{NO}_{\mathrm{x}}$, $\mathrm{HNO}_{3}, \mathrm{PAN}$, formaldehyde and acetaldehyde, while wet deposition through scavenging by clouds removes predominantly $\mathrm{HNO}_{3}$, formaldehyde and $\mathrm{H}_{2} \mathrm{O}_{2}$. The chemical mechanism includes the heterogeneous conversion of $\mathrm{NO}_{\mathrm{x}}$ to $\mathrm{HNO}_{3}$ on sulfate aerosols according to Dentener and Crutzen (1993), as well as a description of sulfur chemistry (Jeuken, 2000).

\subsection{Lightning $\mathrm{NO}_{\mathrm{x}}$ emissions}

The lightning $\mathrm{NO}_{\mathrm{x}}$ emissions in the model are based on the widely used parameterization of Price and Rind (1992). The spatial distribution of lightning, as well as the intensity, is calculated using the heights of cloud tops in systems of deep convection. To discriminate between the efficiency of lightning $\mathrm{NO}_{\mathrm{x}}$ production over the oceans relative to land, we have assumed a ratio of 1:10 in production efficiency, following Levy et al. (1996). The lightning $\mathrm{NO}_{\mathrm{x}}$ production efficiency in cloud-to-ground discharges has been scaled to account for the higher efficiency in high latitudes (Mackerras and Darveniza, 1994). The $\mathrm{NO}_{\mathrm{x}}$ emissions are uniformly distributed between cloud base and cloud top, proportional to air-density. By scaling the lightning $\mathrm{NO}_{\mathrm{x}}$ emissions with meteorological parameters, interannual variability in the model meteorology is also reflected in interannual variability in the lightning $\mathrm{NO}_{\mathrm{x}}$ emissions. The total annual simulated lightning $\mathrm{NO}_{\mathrm{x}}$ emissions over the period 1979-1993 are $4.6 \pm$ $0.3 \mathrm{TgN} \mathrm{yr}^{-1}$.

In our sensitivity experiments, we have used the vertical lightning $\mathrm{NO}_{\mathrm{x}}$ distribution profiles as given in Pickering et al. (1998). In this work, the vertical distribution depends on the location (tropics or extra-tropics), and surface characteristics (land or sea). Also, we have implemented a lightning $\mathrm{NO}_{\mathrm{x}}$ parameterization developed by Meijer et al. (2001). This follows the principles of Price and Rind (1992), however, the occurrence and intensity of lightning $\mathrm{NO}_{\mathrm{x}}$ emissions is coupled to the convective precipitation in the model. This was shown to correlate well with space-based observations of lightning flash rates over Europe, and was tested against $\mathrm{NO}_{\mathrm{x}}$ observations in the extra-tropics. The main difference between the two approaches is the fraction of the emissions occurring in the tropics. In the new parameterization, this fraction decreases from $80 \%$ to $70 \%$, which agrees better with independent estimates (Levy et al., 1996; Price and Rind, 1992).

\subsection{Labeled tracers}

To attribute photochemically produced ozone to the different processes in our model, we applied a tracer labeling technique. The assumption that ozone formation in the troposphere is $\mathrm{NO}_{\mathrm{x}}$-controlled (Crutzen, 1988) implies that NOto- $\mathrm{NO}_{2}$ conversion by peroxy-radicals can be used to diagnose ozone formation. Thereto, we have introduced labeled tracers of $\mathrm{NO}_{\mathrm{x}}$, the most important $\mathrm{NO}_{\mathrm{y}}$ species, and ozone. The $\mathrm{NO}_{\mathrm{x}}$ tracers are labeled according to their source category, representing emissions from lightning, biomass burning, nonagricultural soils, and industrial sources. When a labeled $\mathrm{NO}$ molecule is converted to $\mathrm{NO}_{2}$ by a peroxy radical, the subsequent photolysis of $\mathrm{NO}_{2}$ yields an ozone molecule labeled accordingly. Furthermore, tropospheric ozone introduced through stratosphere-troposphere exchange (STE) is labeled by tagging molecules once they pass the $100 \mathrm{~Pa}$ level. The labeled tracers participate in all other processes open to their regular, non-labeled counterparts. This approach was tested and discussed in Lelieveld and Dentener (2000).

The sum of all the labeled tracers represents $\sim 90 \%$ of the total ozone concentration in the tropical troposphere. The 
residual of $\sim 10 \%$ that we cannot reproduce in the tracer labeling is simply a result of the chosen approach. The labeled ozone tracers in the model are a diagnostic tool, and not an exact solution of the differential equations governing ozone photochemistry. Although many reaction pathways, including cycling of $\mathrm{NO}_{\mathrm{x}}$ through several reservoir species, are labeled, not all possible routes and recombinations are taken into account. For instance, cycling of $\mathrm{NO}_{2}$ and $\mathrm{NO}_{3}$ through $\mathrm{N}_{2} \mathrm{O}_{5}$ can yield back the original products, or $\mathrm{HNO}_{3}$. The many combinations in which this is possible given five marked tracers (plus one unmarked) is large, and had to be simplified. Also, the production of marked ozone from $\mathrm{NO}+\mathrm{RO}_{2}$ reactions is calculated simply from the reaction fluxes, which can also lead to errors as was discussed extensively in the original work of Johnston and Kinnison (1998), and comments on that work Pöschl et al. (2000). For the purposes in this paper the labeled tracer approach, although clearly not exact, gives very useful information and the ability to diagnose the ozone budget qualitatively.

In the calculations presented in the next sections, the local tropopause height is calculated in the same way as in Peters et al. (2001). We define the tropical tropopause as the level where the temperature lapse rate changes sign. This gave better agreement with the observed tropopause heights (see Peters et al. (2001)) than gradient based methods such as Craig (1965). Due to the coarse vertical resolution, our model underestimates tropopause heights in the tropics by about $20 \mathrm{~Pa}$, which translates to a 1.6 DU underestimate of tropospheric ozone columns assuming a mixing ratio of $100 \mathrm{~Pa}$ at the tropopause.

\section{Observations}

We use the NIMBUS-7 TTOC record (1979-1992) to detect systematic flaws in our model and to gain more insight in the sensitivity of our model calculated ozone. The observations were derived from the TOMS total ozone observations with the Modified-Residual (MR) method (Hudson and Thompson, 1998).

The TTOC record provides twice monthly fields of TTOC, covering all the tropical latitudes where a zonal wave one pattern in total column ozone is observed. The horizontal resolution of the dataset is $2^{\circ}$ longitude $\times 1^{\circ}$ latitude $(230 \times 115 \mathrm{~km}$ at the equator), and through averaging over several orbital passes of the satellite, a picture of the full zonal distribution of TTOC is obtained in several days. Through averaging the observations over 13-15 day periods, errors associated with the scan angle, as well as instrument noise are filtered out. Thus, the product is not suited to study day-to-day variability. The data is available on the internet through http://metosrv2.umd.edu/ tropo/.

Uncertainties in the observations of TTOC are related to the assumed tropopause height as well as the insensitivity of the TOMS instrument to tropospheric ozone near the sur- face. The instrument is progressively insensitive to the signal of ozone originating from altitudes below the stratospheric ozone maximum. The algorithms that were developed to circumvent these problems are explained in detail in Hudson and Thompson (1998). In the MR retrieval algorithm, sonde observations from selected stations in the $\mathrm{SH}$ are used to obtain a-priori information on the zonal distribution of tropospheric ozone, which is thereafter projected onto each grid point of the total column ozone observations to yield the TTOC. The averaging of several sondes to obtain a halfmonth average leads to a standard deviation of $\pm 5.3 \mathrm{DU}$. Therefore, the a-priori zonal ozone distribution cannot be fixed more accurately than this sonde standard deviation, and 5.3 DU is thus the lower limit for the precision in TTOC. This value is comparable to the TOMS instrument accuracy. An independent comparison of TTOC with four ozone sonde stations in the tropics revealed a RMS deviation of 5.1 DU between TTOC and sondes (Thompson and Hudson, 1999). This value is expected to increase with distance from the sonde stations used in the algorithm, and is probably larger in the $\mathrm{NH}$ than in the $\mathrm{SH}$, since the underlying zonal wave one pattern used in the retrieval was based on SH ozone sondes. However, since there is no objective way to define the deviations at other locations, the overall standard deviation of the TTOC product is given by $\sigma=5.3 \mathrm{DU}$ over the whole domain.

The Nimbus-7 TTOC record (1979-1992) has been evaluated in two ways with ozonesonde data. Note that these comparisons are mostly performed in the Southern Hemisphere tropics (A. M. Thompson et al.: The 1998-2000 SHADOZ (Southern Hemisphere ADditional OZonesondes) tropical ozone climatology. 2. Stratospheric and tropospheric ozone variability and the zonal wave-one, J. Geophys. Res., submitted, 2002, from now on: A. M. Thompson et al., submitted manuscript, (2002)), since the available Northern Hemisphere tropical data are restricted to campaign data (Thompson et al., 2000) and to stations at Suriname (5N, 55W) and Malaysia (S. Yonemura et al.: Tropospheric ozone climatology over peninsular Malaysia from 1992 to 1999, J. Geophys. Res., in press, 2002). First, the limited ozonesonde data for the 1979-1992 period agreed with the TTOC satellite product within 6-7 DU on average (Thompson and Hudson, 1999). Second, a statistically averaged annual dataset was prepared from Nimbus-7 TTOC and compared to the 1998-2000 SHADOZ ozonesonde record in four regions: tropical Atlantic, central Pacific, eastern Pacific and Indonesian maritime continent. Excellent agreement in TTOC magnitude and seasonality was found in the central Pacific TTOC compared to sondes at Samoa (14S, 171W). The TTOC seasonality over the eastern Pacific and Indonesian maritime continent compared well to ozonesonde seasonal patterns at San Cristobal $(1 \mathrm{~S}, 89.6 \mathrm{~W})$ and Watukosek, Java (7.5S, $113 \mathrm{E})$, respectively, but tended to be too high in magnitude. Over the Atlantic, comparison of the TTOC annual mean with ozonesondes over Ascension Island (6S, 15W) suggests 

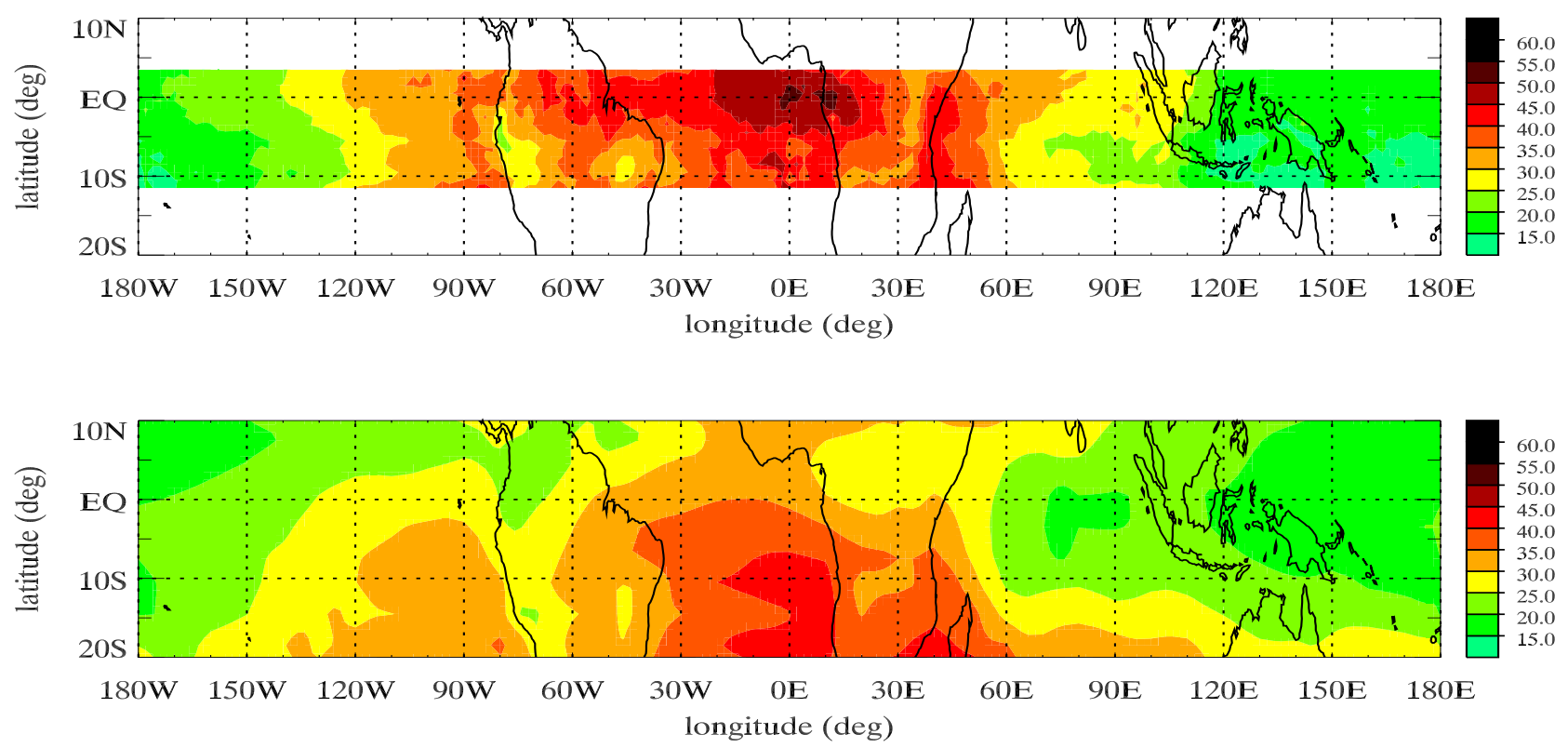

Fig. 1. Observed (top) and model calculated (bottom) distribution of TTOC in September 1992. Note the widespread underestimate of TTOC over the tropical Atlantic Ocean and adjacent continents.

an overestimate of 5-8 DU on average during the period from July-October 1998-2000.

It should be noted that differences among several retrieval algorithms of TTOC (e.g. Ziemke et al. (1999), Fishman and Larsen (1987)) can be quite large, also compared to the reported standard deviation of 5.3 DU. No comprehensive intercomparison has been published so far, although Martin et al., (R. V. Martin et al.: Global model analysis of TOMS and in-situ observations of tropical tropospheric ozone, J. Geophys. Res., submitted, 2002) have noted a tendency for tropical Atlantic ozone from TOMS-based data to run high relative to in-situ measurements, particularly in the second half of the year. Our experiences with working with the Ziemke et al. (1999) data suggest that the MR method generally gives higher values of TTOC, and several regions are suspected to experience unwanted aerosol influences in the MR method (A. Frolov, personal communication). A detailed quantification of the uncertainties of individual locations in the MR method is beyond the scope of this study, as is an intercomparison between the different TTOC datasets. More insight in the value and representivity of these datasets can be obtained through actively using them, as we do in this study. For now, we therefore take the MR-TTOC data "as is", and are cautious not to overinterpret our results.

Alternatively, ozone sondes and in situ measurements from campaigns such as TRACE-A, PEM, NOXAR, or MOZAIC could be used to test our models performance in the tropics. The data acquired in these campaigns generally include detailed vertical information on several trace species and meteorological parameters. However, there is an important trade off to consider that can be seen as a choice between the amount of detail of information and the areal and temporal coverage. The individual campaigns usually cover periods of several weeks in a specific year, and focus on a limited geographical region. Especially near the surface, they are often influenced by local pollution or particular small scale meteorological conditions (e.g. sea-breeze, orographic flows). This is especially disadvantageous when comparing to global models that generally apply coarse resolutions and parameterizations not designed to capture these small scales. Ozone sondes and in situ measurements are much better suited to study smaller temporal and spatial scales, or the effect of a single process (e.g. biomass burning or convection). These data would therefore form an ideal basis to improve possible model shortcomings, which is the next step in our research. However, in this work we take advantage of the global, multiyear TTOC record to firstly isolate the regions, seasons, and processes that require improvement.

\section{Measure of error}

Figure 1 (top) shows the observed TTOC distribution in September 1992, when biomass burning emissions were particularly strong. The TOMS-based TTOC is in excellent agreement with in-situ observations (Thompson et al., 1996; Thompson and Hudson, 1999). Ozonesondes at Ascension Island and the near-coast locations of Brazzaville (4S, $15 \mathrm{~W})$ and Natal $(6 \mathrm{~S}, 35 \mathrm{~W})$, averaged $50 \mathrm{DU}$ in September 1992. On aircraft flights out of Ascension during October 1992, TTOC from lidar measurements ranged from 4555 DU (Browell et al., 1996). 
The South Atlantic ozone maximum clearly stands out with values $>50 \mathrm{DU}$, gradually decreasing with distance from the Atlantic, reaching minimum values between 10 and 20 DU over the Pacific Ocean. The comparison with model simulation of TTOC for the same year and month in Fig. 1 (bottom) shows distinct differences. The absolute values of the TTOC often differ by more than the one sigma (5.3 DU) standard deviation of the measurements, and many smaller scale features are not reproduced. The discrepancies are largest over the Atlantic Ocean, where a systematic mismatch is seen between observations and model calculations. In contrast, the model reproduces the TOMS observations quite well over the Pacific Ocean. This is consistent with earlier results (Peters et al., 2001), based on a comparison with ozone sondes from Samoa, Ascension and Natal.

Beside this "Atlantic mismatch", there are two other important features that appear from Fig. 1. Firstly, the amount of detail in the observations is larger. This can be partly attributed to the higher resolution of the observations, but it is also caused by a lack of variation in the model's monthly emission data. To account for the different resolutions of the datasets, we interpolated the model results to the $2^{\circ} \times 1^{\circ}$ degree resolution of the TTOC observations and we applied a zonal running average to the TTOC observations, with a window size equal to the zonal model grid-size ( $5^{\circ}$ latitude). This filters out strong local features in the observations at resolutions smaller than the model grid, which cannot be reproduced by the model.

Secondly, it is important to note that variations in the meridional direction are small compared to the large zonal variation. Since the area depicted in Fig. 1 encompasses only 5-6 model grid boxes in the meridional direction (appr. $15^{\circ}$ degrees), the model can not reproduce fine scale structures in the meridional direction. Moreover, the zonal TTOC distribution is typically a feature on large (planetary) scale, while meriodional variations within the tropics are on a much smaller, almost local scale. Therefore, the next step in our comparison is to take the meridional average of the respective datasets at each longitude, which yields the zonal distribution of TTOC.

\subsection{Zonal TTOC distribution}

Figure 2 shows the derived zonal TTOC distribution in September 1992 for both datasets. It has already been pointed out that the MR-TTOC for September 1992 agrees well with the available sonde data near the Atlantic (location of peak in zonal maximum, Fig. 2). More comprehensive ozonesonde data, collected in 1998-2000 from 10 stations across the entire tropical zone, confirm the wave-one pattern (Thompson et al., 2002). A longitudinal cross-section of those observations, shows the wave to be associated with elevated ozone ( $>45 \mathrm{ppbv}$ ) concentrated in the free troposphere between 50W and 50E (A. M. Thompson et al., submitted manuscript, 2002). The distribution and intensity of

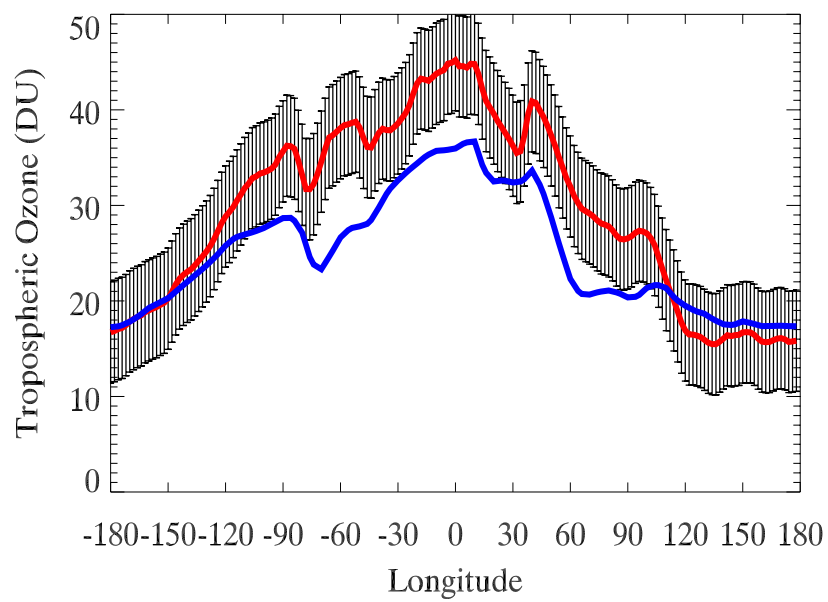

Fig. 2. The meridionally averaged zonal TTOC distribution in model calculated (blue) and satellite retrieved (red) TTOC for September 1992. This distribution is used to define a measure of error according to Eq. (1). The shaded lines denote one-sigma standard deviation (5.3 DU). Atlantic ozonesonde and aircraft ozone data (taken within longitudes $35 \mathrm{~W}$ to $15 \mathrm{E}$ ) during September and October 1992 fall within the shaded region.

the higher-ozone feature, hence the magnitude of the wave, varies with time of year, but it is always present. The regions of enhanced ozone correspond to locations where ozonesondes and other observations implicate biomass burning, lightning (Thompson et al., 1996), large-scale subsidence ( $\mathrm{Kr}$ ishnamurti et al., 1996) and stratospheric intrusions (Baray et al., 2000) as possible ozone sources.

The figure clearly shows the zonal extent of the Atlantic mismatch, characterized by model calculated TTOC values that are consistently lower than the observations over the $90 \mathrm{~W}$ to $90 \mathrm{E}$ region. Although this mismatch maximizes each year in September, other months show a similar problem. The TTOC distribution depicted in Fig. 2 is chosen as the focal point of our comparison. Conveniently, the TTOC retrieval algorithm uses the meridional extent of the zonal wave one pattern to distinguish tropical air masses from extratropical air masses. Thus, this pattern is always present in the satellite observations, and points that do not qualify as "tropical" in the retrieval algorithm are not included in the comparison to our model calculations.

To make an objective comparison between the observed and modeled zonal TTOC distributions, a mathematical measure of error is introduced, which consists of two components. First, we define $\epsilon_{1}$, which is simply the correlation (r) between the observed and modeled zonal wave one pattern in Fig. 2. The parameter $\epsilon_{1}$ indicates how well the horizontal gradients in the zonal TTOC distribution are reproduced, and how well transitions in TTOC induced by the land-sea distribution for instance are captured. The shape of this pattern is influenced amongst other factors by the location of the Inter Tropical Convergence Zone (ITCZ), the presence 
of biomass burning plumes, or the occurrence of large scale convection and associated lightning. Increasing values of $\epsilon_{1}$ denote a better representation of these zonal gradients. It is important to note that $\epsilon_{1}$ is not influenced by the absolute value of TTOC, and its value will increase only when the zonal gradients in the model calculations better fit the observations. This is advantageous because it excludes the errors in the measurements and model that are introduced through uncertainties in the tropopause height. On the other hand, the parameter $\epsilon_{1}$ cannot be used to assess the absolute fit between the observations and the calculations.

Therefore, we also introduce a second parameter, $\epsilon_{2}$, that is defined as the absolute deviation between observations and measurements, scaled by the standard deviation of the observations:

$\epsilon_{2}(t)=\frac{1}{N_{\text {lon }}} \sum_{\text {lon }} \frac{|\overline{T O M S(t)}-\overline{T M 3(t)}|}{\sigma_{T O M S}}$

Where $\overline{T O M S(t)}$ is the observed zonal distribution of TTOC for each month (t), and $\overline{T M 3(t)}$ is the model calculated zonal distribution of TTOC for each month. The value of $\epsilon_{2}$ will decrease as the discrepancy between observations and calculations decreases.

The number of longitudes used in the summation can vary depending on the scale we want to look at. For instance, in the analysis of the variability (Sect. 5), we analyze 14year time series of $\epsilon_{2}$ at each location $\left(\mathrm{N}_{\text {lon }}=1, \mathrm{t}=168\right)$, while for the analysis of our sensitivity runs (Sect. 8) we subdivide the zonal domain into only two regions; a Pacific region $\left(\mathrm{N}_{\text {lon }}=90, \mathrm{t}=168\right)$ and an Atlantic region $\left(\mathrm{N}_{\text {lon }}=90\right.$, $\mathrm{t}=168$ ). Together, $\epsilon_{1}$ and $\epsilon_{2}$ enable us to quickly and objectively quantify the agreement with the TTOC observations, and intercompare the results of different model simulations.

\subsection{Algorithm test}

In order to assess the robustness of our algorithm, and to get an indication of the sensitivity of $\epsilon_{1}$ and $\epsilon_{2}$, we have applied our measure of error to a series of test distributions of ozone in a Monte-Carlo like approach. Thereto, an ensemble of one hundred 3-dimensional ozone distributions was created, in which each gridpoint of an actual model calculated ozone distribution was randomly perturbed by an average of $\pm 10 \%$. These random perturbations represent the effects of for instance anomalous winds, convective venting, or unexpected emissions of ozone precursors that could disturb the ozone concentration within a gridbox in a non-systematic way, that is nevertheless substantial in magnitude. Next, we have integrated the columns, averaged to make the zonal pattern, and then calculated the yearly values of $\epsilon_{1}$ and $\epsilon_{2}$ for each of the one hundred perturbed distributions. The distribution of $\epsilon_{1}$ and $\epsilon_{2}$ in this ensemble reveals the spread that can be expected from relatively large, but random perturbations. Any change in $\epsilon_{1}$ and $\epsilon_{2}$ that is significantly larger

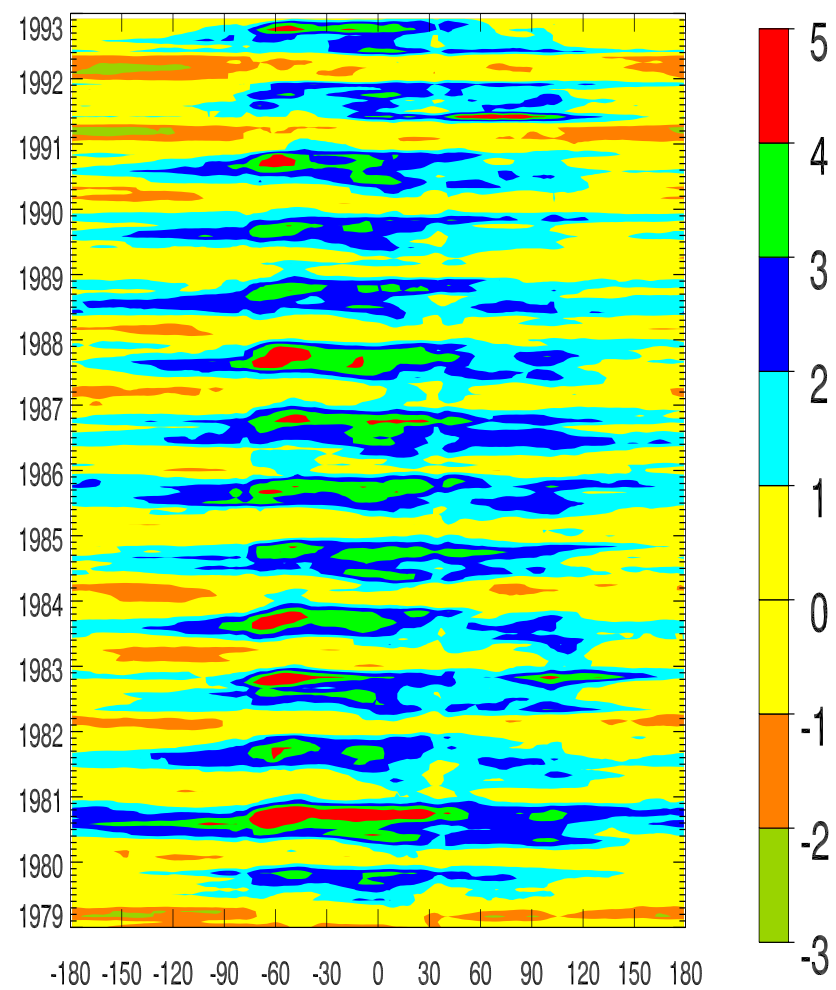

Fig. 3. Hövmoller plot of $\epsilon_{2}$ as a function of longitude for the period 1979-1992. A value of 1 denotes a difference of 5.3 DU (1- $\sigma)$ between model and observations. The $+/$ - signs were added to the figure to signify model underestimates or overestimates repectively.

(more than $1 \sigma$ ) than this, should then be seen as a systematical change of our model calculated ozone field.

From our one hundred member ensemble, we have derived a one-sigma standard deviation of \pm 0.001 for $\epsilon_{1}$, and \pm 0.01 for $\epsilon_{2}$. We can thus say that the small differences we report in Sect. 6 and Table 2 represent a systematic difference between the calculated ozone fields from different years, and under different scenarios.

\section{Comparison of TTOC}

As a first step, we calculate the values of $\epsilon_{2}$ for each longitude and each month $(\mathrm{t}=168)$ of our multi-year simulation. The result is shown in Fig. 3, where a negative sign indicates that the model calculated values are higher than the observations. It shows that the values of $\epsilon_{2}$ range from $0-2 \sigma$ (appr. 0-10 DU) over the tropical Pacific, to more than $3 \sigma$ (appr. 16 DU) over the tropical Atlantic. The largest underestimates occur during August through November. The model calculated values of TTOC are generally lower than the observations. The only time the model overpredicts the TTOC values is in Dec-Jan-Feb over the Pacific Ocean.

It is clear from Fig. 3 that the Atlantic mismatch is the most serious problem in our comparison, and that it is an annually 


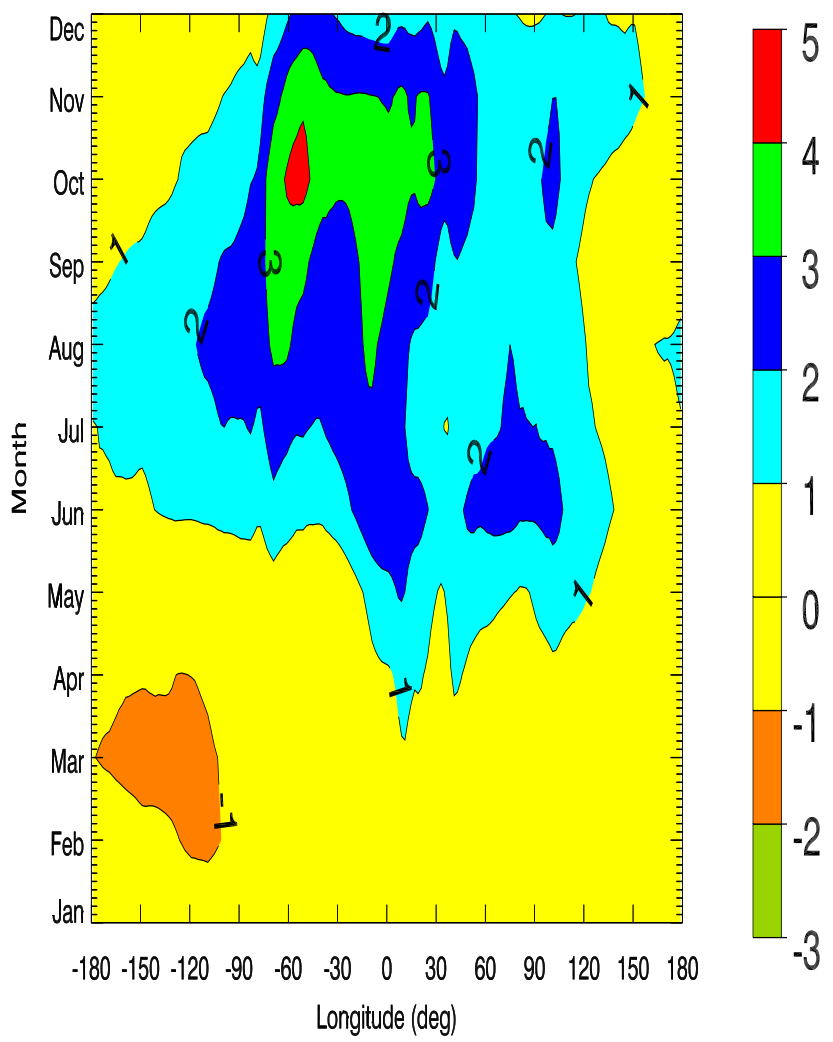

Fig. 4. 14-Year average seasonal cycle of $\epsilon_{2}$ as a function of longitude. A value of 1 denotes a difference of 5.3 DU (1- $\sigma)$ between model and observations. The $+/$ - signs were added to the figure to signify model underestimates or overestimates repectively.

recurring feature. In contrast, high values of $\epsilon_{2}$ over the Pacific Ocean appear for several years, but not in all. To separate these systematic differences from the ones that occur occasionally, we have decomposed each time series of $\epsilon_{2}$ into a seasonal cycle, and a component of interannual variability. For a discussion of the interannual variability in TTOC we refer to Peters et al. (2001). The seasonal cycle of $\epsilon_{2}$ is shown in Fig. 4. The figure confirms that most of the Atlantic mismatch is caused by seasonal differences. On average, the seasonal cycle contains $75 \%$ of the variance of the $\epsilon_{2}$ time series over this region. In contrast, the seasonal cycle of $\epsilon_{2}$ over the Pacific Ocean explains less than $50 \%$ of the original variance. If we consider the relative errors, both deviations translate to ca $30 \%$ of the observed TTOC. From this, we can conclude that the most important model improvements should focus on the seasonality of TTOC over the Atlantic Ocean. Possibly, the Pacific region would profit from such improvements as well, since the two regions are coupled through transport.

\section{Influence of transport}

The coupling between the regions through transport is not the same in each year due to the occurrence of anomalous meteorological conditions such as those induced by ENSO. Through the use of ECMWF wind fields for each year, we have included this transport variability, and in Peters et al. (2001) showed that the effect of ENSO on TTOC is present in our multi-year simulation. In this section, we will apply our measure of error to quantify the influence of transport on our results.

We compare each year of TTOC observations with each year of our multi-year simulation. In our multi-year simulation, we have 15 years of calculated TTOC, which differ in meteorology (including lightning), stratospheric upper boundary conditions for ozone, and the anthropogenic emissions which include trends over the 1979-1993 period. In this section, we use yearly averaged values for 1979-1992 of the monthly calculated $\epsilon_{1}$ to assess the performance of our model. Since $\epsilon_{1}$ is independent of the absolute values of TTOC, the influence of increasing emissions in the multiyear simulation is largely excluded in this comparison. Thus, any year-to-year difference in $\epsilon_{1}$ is due to changes in meteorology (including changing lightning patterns).

For each year of the TOMS observations (1979-1992, n = 14), we have calculated 14 values of $\epsilon_{1}$; one value for each year of simulations $(1979-1992, \mathrm{~m}=14)$. These individual values of $\epsilon_{1}$ denote the success in simulating the observed zonal distribution of TTOC, given the specific meteorological conditions of each of the 14 simulated years. The average $\epsilon_{1}$ of these individual years would represent the value when a random year of meteorology is applied, while there is one value of $\epsilon_{1}$ that corresponds to the correct meteorology matching the year of TTOC observations.

Figure 5 shows the multi-year average value (open diamonds) and range of interannual variation (bars) for each of the 14 years TTOC observations, as well as the values of $\epsilon_{1}$ for the model year corresponding to the year of observations (filled diamonds). The simulations performed with actual meteorology consistently perform better than average. In fact, the simulation with actual meteorology generally ranks higher than any other year. This is due to the fact that meteorological conditions determine to a large extent the location of local ozone maxima, as well as the zonal gradients in TTOC. Although the differences between a correlation of 0.7 and 0.84 might seem small, the fact that these differences show up in a yearly and meridionally averaged TTOC distribution indicates that the individual differences are in fact quite large, and certainly significant given the sensitivity of $\epsilon_{1}$ (Sect. 4.2).

From the figure one can also see that the 14-year average value of $\epsilon_{1}$ varies from year-to-year, as does the range. This shows that some years of observations are more difficult to model than others presumably because their specific conditions are more difficult to capture. This is obvious for 1982/83, when El Niño conditions prevailed. While the simulation with actual meteorology performs well, some other years show a poor correlation. This indicates that in such a year, the zonal TTOC distribution can not be mod- 


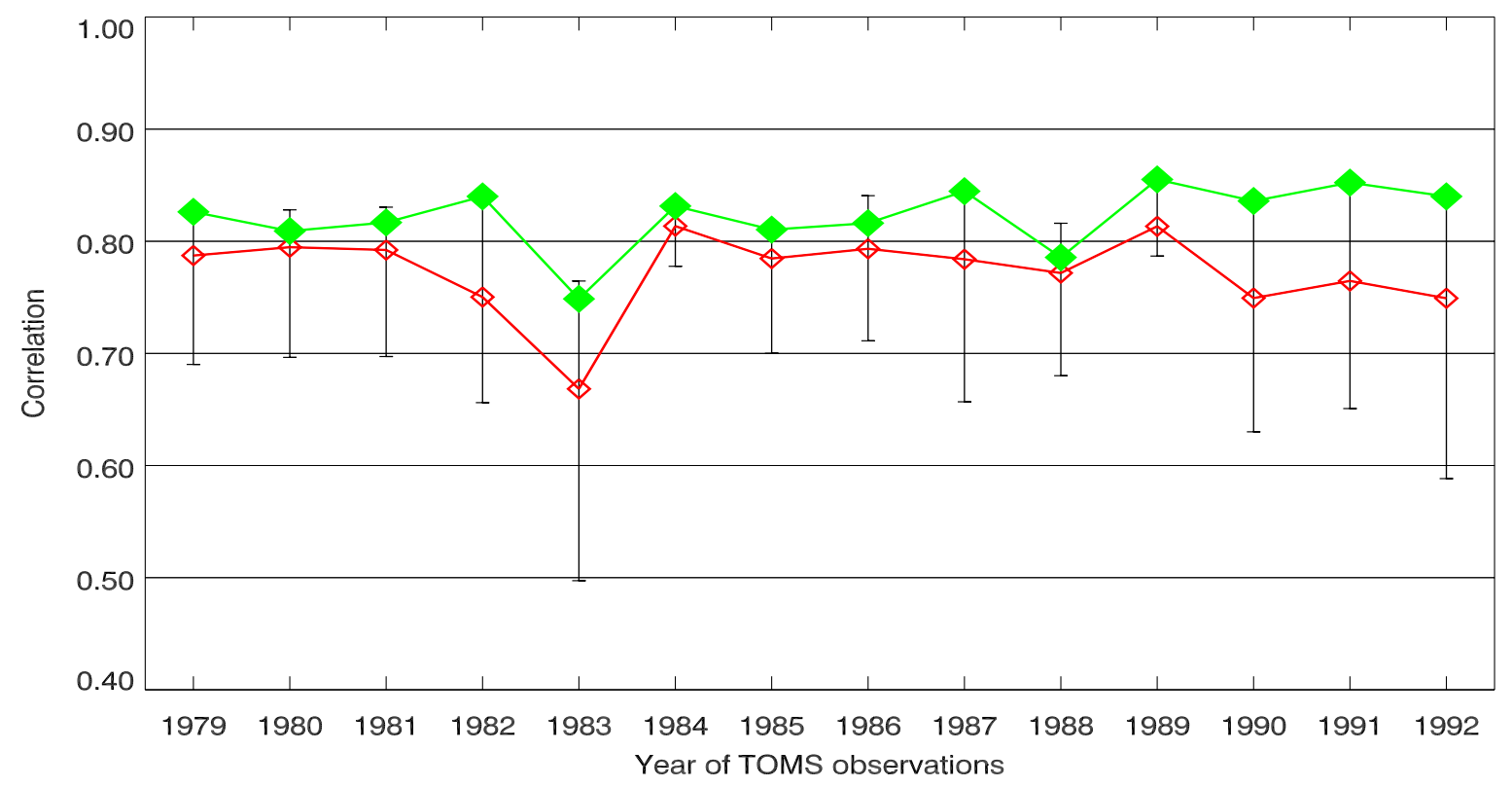

Fig. 5. Correlation coefficient $\left(\epsilon_{1}\right)$ between the zonal TTOC distribution in observations and simulations. For each year of TTOC observations (1979-1992) correlations were calculated with each year of a multi-year simulation with our CTM (1979-1992). The bars denote the range of correlations, the red diamonds are the averages. This value is representative for a simulation with "climatological" meteorology. The green diamonds signify the correlation when the correct meteorology of the year of observations is applied to the model.

eled very well if one does not consider the specific meteorological conditions during ENSO. The fact that the maximum of $\epsilon_{1}$ for 1983 is the lowest in the whole series shows that other processes than transport that change during ENSO also influence the shape of the zonal TTOC distribution. Such processes include the occurrence of wildfires following anomalous droughts. Although this was shown to have a large impact on TTOC (Chandra et al., 1998; Thompson et al., 2001), it was not included in our multi-year model simulations. Adding this variability in emissions to the model is a difficult challenge, for which tools are currently being developed (B. Duncan, R. Martin, A. Staudt, R. Yevich and J. Logan: Interannual and Seasonal Variability of Biomass Burning Emissions Constrained by Remote-Sensed Observations, manuscript in preparation, 2001).

\section{Role of photochemistry}

Beside the previously mentioned wildfires, other sources contribute to the photochemical production of ozone in the troposphere, and thus partly determine the zonal distribution of TTOC as depicted in Fig. 2. By using the labeled tracers (see Sect. 2.4), we have calculated the contribution of several tropospheric ozone sources to the modeled TTOC distribution. The processes that were thus separated are photochemical ozone production from lightning, industrial, biomass burning, and soil $\mathrm{NO}_{\mathrm{x}}$ emissions, as well as the contribution from the stratospheric influx of ozone. Figure 6 shows the contribution of these processes to the modeled zonal TTOC distribution in September 1992.

Ozone production from industrial $\mathrm{NO}_{\mathrm{x}}$ emissions contributes several DU to the modeled ozone concentration. There is only very little difference in zonal direction, because the most important source is located in the NH extratropics. Transport in longitudinal direction by the powerful jet streams of the $\mathrm{NH}$ and $\mathrm{SH}$ occurs more rapidly than meridional transport to the tropics and across the ITCZ, leading to a largely zonally invariant distribution in the tropics.

Lightning $\mathrm{NO}_{\mathrm{x}}$ emissions in the tropics are stronger over the continents than over the oceans. Yet, the distribution of TTOC from lightning $\mathrm{NO}_{\mathrm{x}}$ does not show much structure in zonal direction, because the $\mathrm{NO}_{\mathrm{x}}$ enriched air is brought into the middle and upper free troposphere, where transport is fast, and the lifetime of ozone relatively long. The monthly mean signal of ozone from lightning $\mathrm{NO}_{\mathrm{x}}$ is therefore seen throughout the tropics, adding 5-8 DU of ozone to most columns. The strongest influence is seen over the Atlantic Ocean and South American continent.

An almost equal contribution to TTOC comes from stratosphere-troposphere exchange. However, most of this ozone is located at the edges of the domain in our analysis, where the subtropical jet sometimes penetrates far equatorwards. This happens at locations where the jetstream is disturbed most frequently; near surface orography and landsea barriers. Thus, most of the stratospheric ozone encountered in the tropical troposphere in our model has crossed the tropopause in the sub-tropics, and is subsequently trans- 


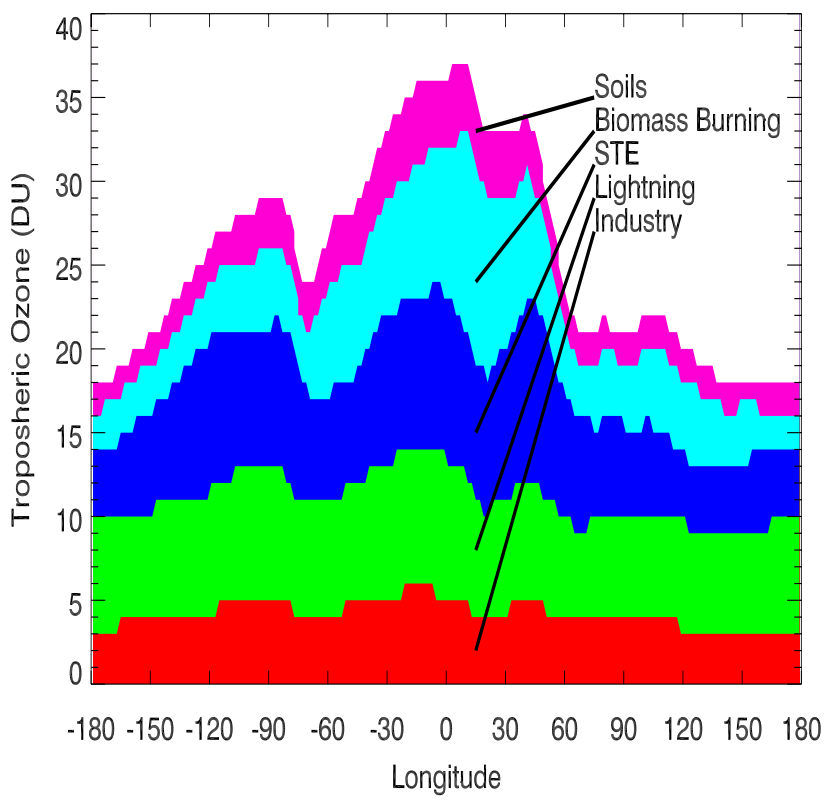

Fig. 6. Absolute contribution of several processes to the modeled TTOC distribution. Processes include photochemical production of ozone following $\mathrm{NO}_{\mathrm{x}}$ emissions from soils, lightning, biomass burning and industrial sources, as well as ozone from stratospheretroposphere exchange. Values for September 1992.

ported equatorwards from these locations where disturbances in the jetstream occur.

The strongest contributors to the "wave one" character of tropical TTOC are soil $\mathrm{NO}_{\mathrm{x}}$ emissions and biomass burning $\mathrm{NO}_{\mathrm{x}}$ emissions. Both these sources are terrestrial surface sources (50\% of soil emissions in the tropics), which maximize over South America and Africa. The ozone produced from these $\mathrm{NO}_{\mathrm{x}}$ emissions is transported more slowly in the lower free troposphere, and has a shorter lifetime there. It therefore slowly accumulates over the Atlantic, but exerts only little influence on the more distant tropical Pacific region.

The seasonality of ozone from biomass burning (not shown) is very similar to the seasonality of $\epsilon_{2}$ in Fig. 4. In contrast, ozone produced from lightning $\mathrm{NO}_{\mathrm{x}}$ emissions displays its maximum in April-May-June, while ozone produced from soil emissions is almost constant throughout the year. This again suggests that biomass burning could be partly responsible for the observed Atlantic mismatch. To see which part of our treatment of biomass burning could be the cause of the seasonal ozone underestimate, we have performed a sensitivity analysis.

\section{Sensitivity analysis}

Beside our treatment of biomass burning emissions, the sensitivity analysis includes simulations to investigate uncertain-
Table 2. Experiments conducted and their values of the parameter $\epsilon_{1}$ or $\epsilon_{2}$. Experiments that meet the criteria described in Sect. 8.1 are displayed in boldface, and discussed in the text. Improvements in $\epsilon_{1}$ are achieved from a more than 0.001 increase in value, and improvements in $\epsilon_{2}$ from a 0.01 decrease.

\begin{tabular}{|c|c|c|c|}
\hline Experiment & $\epsilon_{1}$ & $\epsilon_{2, P a c}$ & $\epsilon_{2, A t l}$ \\
\hline Base & 0.842 & 0.77 & 1.80 \\
\hline \multicolumn{4}{|c|}{ Biomassburning } \\
\hline $2 \mathrm{x} \mathrm{NO}_{\mathrm{x}}$ & 0.848 & 0.71 & 1.58 \\
\hline $2 \times \mathrm{CO}$ & 0.843 & 0.73 & 1.71 \\
\hline 2x NMHC & 0.844 & 0.76 & 1.77 \\
\hline 2x J $\left(\mathrm{HNO}_{3}\right)$ & 0.702 & 0.82 & 1.79 \\
\hline Injection height & 0.853 & 0.72 & 1.52 \\
\hline Alternative calendar & 0.852 & 0.76 & 1.74 \\
\hline \multicolumn{4}{|c|}{ Lightning } \\
\hline $2 \times \mathrm{NO}_{\mathrm{x}}$ lightning & 0.848 & 0.52 & 1.08 \\
\hline $5 \mathrm{x} \mathrm{NO}_{\mathrm{x}}$ oceans & 0.723 & 0.62 & 1.26 \\
\hline Pickering profiles & 0.797 & 0.69 & 1.67 \\
\hline Coupling to conv. prec. & 0.814 & 0.82 & 1.81 \\
\hline land/ocean ratio 2:1 & 0.762 & 0.70 & 1.85 \\
\hline \multicolumn{4}{|c|}{ Other } \\
\hline $5 \mathrm{DU}$ offset & 0.842 & 0.57 & 1.01 \\
\hline
\end{tabular}

ties in the lightning $\mathrm{NO}_{\mathrm{x}}$ emission parameterization. These two processes occur predominantly in the tropics, in contrast to industrial emissions, soil emissions and STE. Although the seasonality and zonal distribution of lightning $\mathrm{NO}_{\mathrm{x}}$ emissions do not match the pattern of $\epsilon_{2}$ (Fig. 4), its large contribution to the ozone budget and large uncertainties in magnitude and distribution justifies a more detailed look at its parameterization.

\subsection{Strategy}

To ensure an objective intercomparison between different model simulations, we now define $\epsilon_{2}$ for two different regions. The first region encompasses all longitudes between $90 \mathrm{~W}$ and $90 \mathrm{E}$ ( $\mathrm{N}_{l o n}=90$, "Atlantic"), and the other region encompasses the longitudes outside this area (180W-90W and $90 \mathrm{E}-180 \mathrm{E}, \mathrm{N}_{\text {lon }}=90$, "Pacific"). Since the good performance of the model over the Pacific Ocean was determined independently by comparison with ozone sondes (Peters et al., 2001), our strategy to determine whether a simulation constitutes an improvement over our base run is: 1) ensure that $\epsilon_{2}$ for the Pacific fit does not increase; 2) achieve a decrease of $\epsilon_{2}$ for the Atlantic mismatch, and 3) try to increase the value of $\epsilon_{1}$. Only when these three criteria are met, a systematic improvement of modeled TTOC has been achieved. This has turned out to be a very strict constraint due to the large number of observations and the scale of the phenomenon. All the sensi- 
tivity simulations pertain to the year 1992 .

Table 2 presents an overview of all the sensitivity simulations that were performed, and their yearly average values of $\epsilon_{1}$ and $\epsilon_{2}$ The base simulation is the model as used in Peters etal. (2001) as well as in the previous sections of this work. The simulations that meet the criteria described above are highlighted in boldface. These simulations are discussed briefly in this section. We repeat that the aim of these simulations was to prioritize directions for further research. Therefore, the analysis and discussion of these simulations will be only brief, and simulations that did not qualify as improvements will not be addressed.

Three of the possible improvements are related to biomass burning. Simulations were performed with an increased injection height of biomass burning products, double $\mathrm{NO}_{\mathrm{x}}$ emissions from biomass burning, and an alternative fire calendar, respectively. These experiments increase the amount of $\mathrm{NO}_{\mathrm{x}}$ in the free troposphere over the tropical Atlantic, and thereby increase the photochemical production of ozone. The amount of $\mathrm{NO}_{\mathrm{x}}$ reaching the free troposphere is determined by the complex interaction between emissions, deposition to the surface, oxidation by $\mathrm{OH}$, and convective venting from the planetary boundary layer (PBL).

The efficiency by which an $\mathrm{NO}_{\mathrm{x}}$ molecule contributes to ozone formation depends to a large extent on its lifetime, i.e. its ability to reach the free troposphere and avoid dry deposition or oxidation to $\mathrm{HNO}_{3}$. Due to the dry conditions prevailing during biomass burning events, strong convective systems can be assumed to be absent near large fires. Moreover, $\mathrm{NO}_{\mathrm{x}}$ has a lifetime of only several days in the PBL, and in its oxidized form $\left(\mathrm{HNO}_{3}\right)$ surface deposition is even faster and rainout during convective transport occurs quickly. Therefore, the interaction between meteorology and emissions largely determines whether a $\mathrm{NO}_{\mathrm{x}}$ molecule will reach the free troposphere, or will be oxidized and/or deposited in the PBL. Our three successful experiments influence this interaction in three different ways.

Firstly, we reduce rapid deposition of $\mathrm{NO}_{\mathrm{x}}$ in the PBL and increase the concentration in the free troposphere by distributing the biomass burning $\mathrm{NO}_{\mathrm{x}}$ emissions over the lower $6 \mathrm{~km}$ of the troposphere. Obviously this is arbitrary, but it shows that an improvement would be realized if more biomass burning $\mathrm{NO}_{\mathrm{x}}$ were transported to the free troposphere in our model. This could indicate a lack of transport of biomass burning products from the planetary boundary layer $(\mathrm{PBL})$, which is plausible since this parameterization depends on 6-hourly updated diffusion parameters, that can not adequately capture the diurnal growth and decline of the PBL. Using $\mathrm{Rn}^{222}$, Dentener et al. (1999) already noticed that our model appears to underestimate convective venting of the PBL over the African continent. It could also indicate that biomass burning smoke plumes may reach the free troposphere on their own buoyancy, which is not included in our model. Finally, Yienger and Levy (1995) suggested that post-burning soil emissions of $\mathrm{NO}_{\mathrm{x}}$ could contribute to the emission budget. These emissions could easily reach the free troposphere under unstable or convective conditions occuring after the fire activity has ceased.

In addition, the interaction between transport and biomass burning in the model could be improved through implementation of a more realistic fire calendar. As a result, the location and occurrence of convection would become more consistent with the emissions. The convective vertical exchange of $\mathrm{NO}_{\mathrm{x}}$ decreases in July and August, and increases by $15 \%$ in September and October. This leads to more ozone production in the free troposphere during these months. This agrees well with the findings of Cooke et al. (1996) and Galanter et al. (2000), who applied more detailed alternative fire calendars to point out shortcomings in the inventory of Hao and Liu (1994). The fact that $\epsilon_{1}$ increases significantly indicates that the interaction between biomass burning and convection has a strong influence on the zonal TTOC gradients.

The third important parameter in the description of biomass burning is the emission magnitude. A doubling of the emissions of $\mathrm{NO}_{\mathrm{x}}$ from biomass burning also increases the flux of $\mathrm{NO}_{\mathrm{x}}$ from the planetary boundary layer. Table 3 shows the consequences for the tropospheric ozone budget. The increase in production of ozone is largely balanced by an increase in destruction, as well as by an increase in deposition and an increase in advection of ozone out of the Atlantic region. The net effect of a doubling of the $\mathrm{NO}_{\mathrm{x}}$ emissions is therefore a $2 \mathrm{Tg}$ increase in ozone, which is only 5\% of the tropospheric burden. The effect on the TTOC columns is similar (appr. 2 DU). The effect of increased emissions is more pronounced when it is coupled to the alternative fire calendar. In fact, this simulation shows the highest sensitivity. This suggests that the correct representation of the occurrence and magnitude of biomass burning is an important prerequisite to model TTOC, in agreement with Galanter et al. (2000).

An alternative method to increase the concentration of $\mathrm{NO}_{\mathrm{x}}$ in the free troposphere is through lightning $\mathrm{NO}_{\mathrm{x}}$ emissions. Our current emission magnitude of $4.6 \mathrm{TgN} \mathrm{yr}^{-1}$ is in the lower part of the range of Inter Governmental Panel on Climate Change (IPCC) estimates (4-20 $\mathrm{TgN} \mathrm{yr}^{-1}$ (Prather et al., 2001)), and a doubling would still be within the uncertainty limits (although at the high end of currently used values in global models). Table 2 shows that this would yield an improvement in our comparison to TTOC. Clearly, the impact of this parameter is very large, and an increase in tropical lightning $\mathrm{NO}_{\mathrm{x}}$ emissions would give better agreement with TTOC observations. However, this would also strongly affect the concentrations of ozone in the extra-tropics where $\sim 20 \%$ of the emissions occur in our model. This would lead to a large overestimate of ozone over Europe, the United States, and Asia, where ozone concentrations were previously modeled well (Lelieveld and Dentener, 2000). Although this good agreement could be a fortuitious result of several uncertain processes, we cannot neglect this important side effect of an increase in lightning $\mathrm{NO}_{\mathrm{x}}$ emissions. 
Table 3. Budgets of ozone in the base run, and in a simulation with double $\mathrm{NO}_{\mathrm{x}}$ emissions from biomass burning. The last column shows the difference between both simulations. Numbers are tropospheric integrals over the tropical Atlantic region and adjacent continents [80W-40E,12S-12N] ${ }^{a}$ for the year 1992.

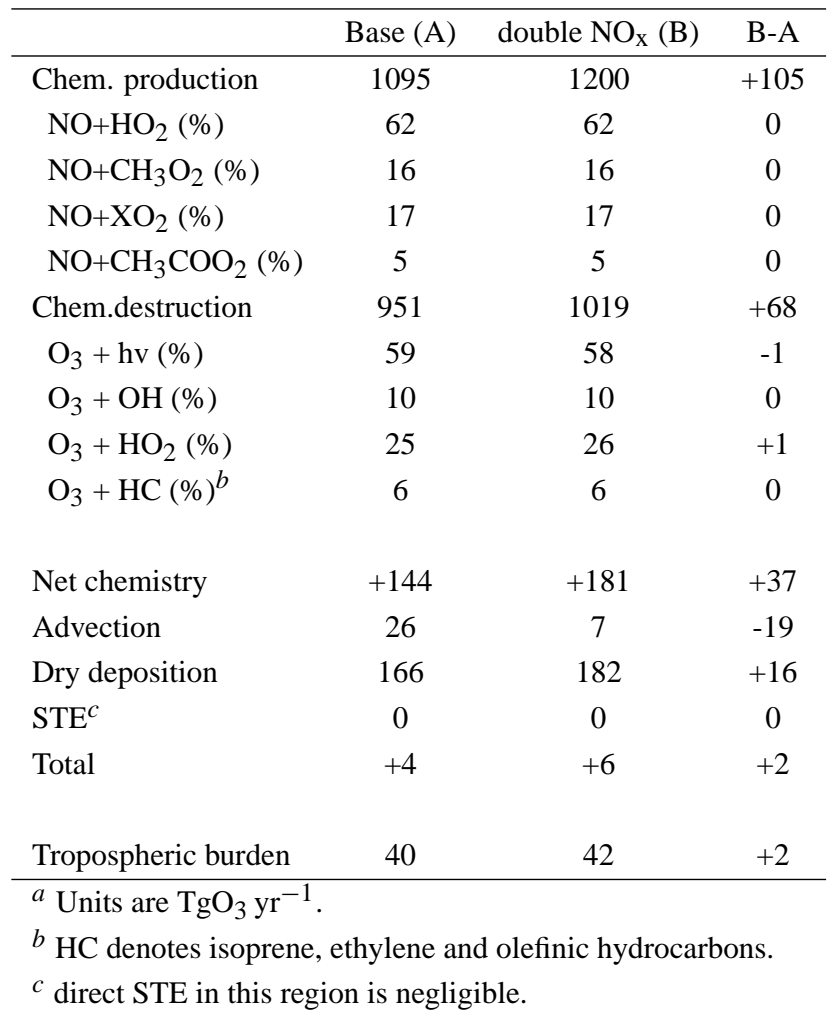

In the alternative parameterization of Meijer et al. (2001), the percentage of extra-tropical emissions would be even higher $(30 \%)$, and the sensitivity over the Northern Hemisphere even larger. Alternatively, we adjusted the lightning $\mathrm{NO}_{\mathrm{x}}$ emissions through changing the land/sea emission ratio, the emission magnitude over the oceans, and through inclusion of vertical distribution profiles of emissions according to Pickering et al. (1998). However, none of these simulations met the criteria of a systematic improvement. For now, we will therefore only state that TTOC in the tropics is very sensitive to lightning $\mathrm{NO}_{\mathrm{x}}$ emissions, and further studies are urgently called for.

\section{Vertical ozone profiles}

To illustrate the results of our sensitivity experiments we present a comparison with selected vertical ozone profiles from several tropical stations. These stations are part of the SHADOZ program, which encompasses 11 ozone sonde stations throughout the tropics. The details of the different stations and a comparison to TOMS data and ground-based measurements can be found in Thompson et al. (2002).
Figure 7 shows six observed (black solid lines) vertical ozone profiles from selected stations and dates from the year 1998, as well as several model calculated profiles for the same day in 1998. These modeled profiles show results from a standard model simulation (blue dashed lines), a simulation with the meteorology of 1997 applied (red dashed lines), and a simulation with doubled biomass burning $\mathrm{NO}_{\mathrm{x}}$ emissions and an alternative fire calendar (green dashed lines).

In many cases, the base simulation captures the general shape of the vertical ozone profile quite well $(\mathrm{a}, \mathrm{b}, \mathrm{c}, \mathrm{d}, \mathrm{f})$, while the simulation with wrong meteorology does not $(\mathrm{a}, \mathrm{b}, \mathrm{d}, \mathrm{f})$. This again illustrates the importance of largescale transport in modeling tropospheric ozone, which we also concluded from our comparison to TTOC in Sect. 6. As expected, adjusting the emission parameterization most strongly influences the stations over the Atlantic Ocean and African continent (c, d, e, f). What is most important to note from the comparison however, is that many features of the individual sonde profiles are not reproduced by the model. Adjusting the biomass burning emission parameterization, or any of the other parameters we tested, does not appear to lead to systematic improvements.

There are several reasons for this. First of all, we mention the difference in vertical resolution, which strongly limits the amount of detail our model can produce. Secondly, we mention the strong damping present in the ozone production, which is obvious from the small differences between the blue and green lines in Fig. 7 and from Table 3. Generally, the ozone mixing ratios increase by approximately $0-5 \mathrm{ppbv}$ at all altitudes, leading to an increase of several Dobson Units when vertically integrated. This difference is small compared to the observed underestimate of TTOC. Finally, the comparison presented is obviously hampered by the representation of different spatial scales. When we try to improve our model through changes in the parameterizations, the response seems to be strongest on the large scales which are dominated by transport in our model, while the smaller scales remain largely unaffected. Since these smaller scales are dominant in the ozone sondes, intercomparing the different model runs does not convey much information on the performance of the models parameterizations. In fact, it is impossible to judge from Fig. 7 which simulation performs better; green or blue?

The comparison illustrates that individual sondes are not the best product to use when testing a CTM. As was recognized previously by Logan (1999), climatologies of ozone observations are more useful in this respect (see also Peters et al. (2001)), even though they lack interannual variability and the density of the measurement network is quite low. We show that the use of TTOC offers a suitable alternative, where the lack of vertical information is "compensated" by the geographical coverage, the frequency of observations, and the length of the observational record. 

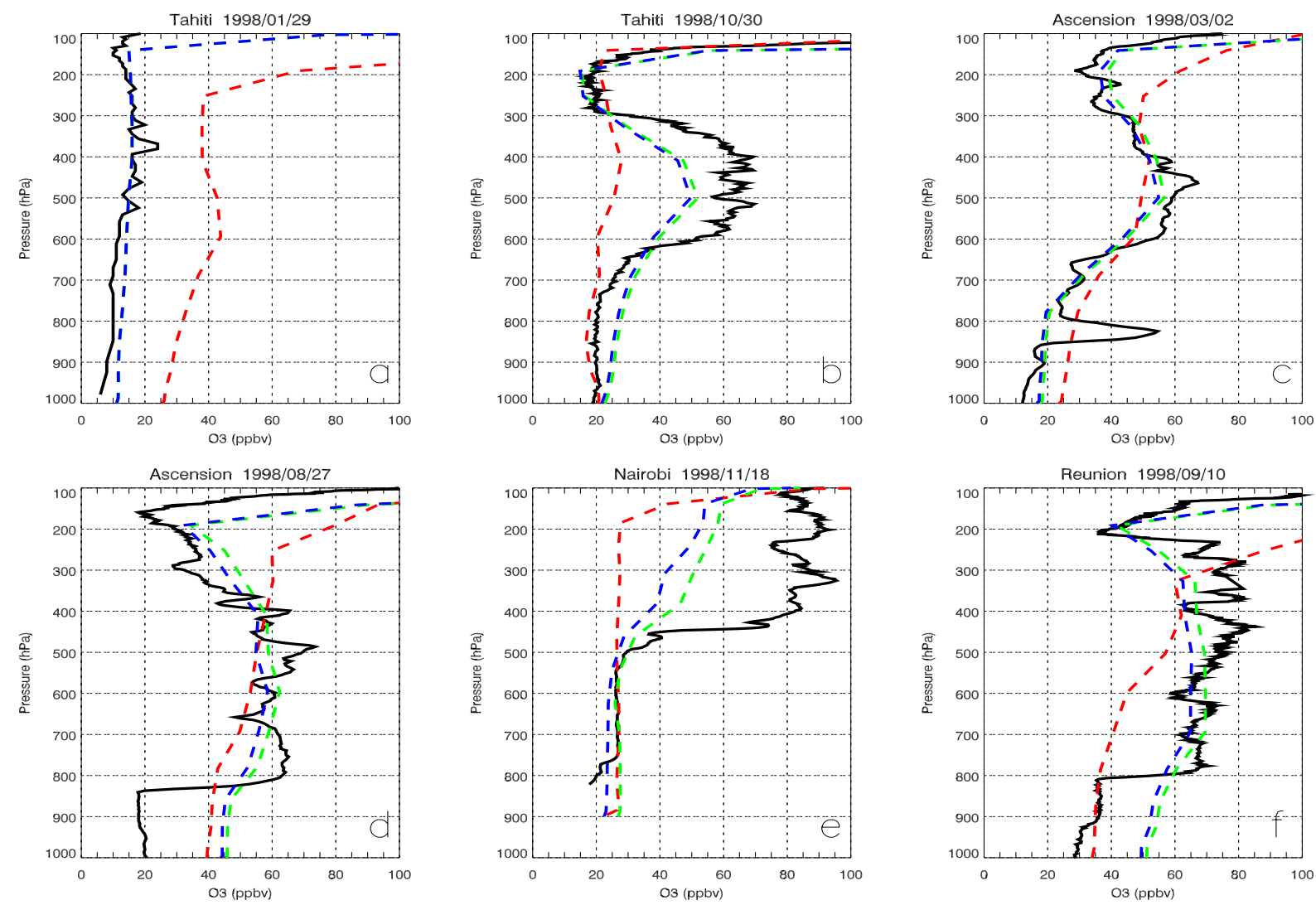

Fig. 7. Selected sondes from six SHADOZ stations in 1998. The profiles show observations (black), a standard model run for 1998 (blue dashed), a model run with meteorology from 1997 (red dashed), and a model run with additional $\mathrm{NO}_{\mathrm{x}}$ emissions and a new fire calendar (green dashed).

\section{Discussion}

Our model evaluation depends to some extent on the accuracy of the TTOC data as well as their assumed standard deviations. The meteorological variability in the model and in the satellite TTOC dataset is very similar, which provides some confidence in the retrieval algorithm applied to produce this dataset. Even though the MR retrieval applies sonde observations from two specific years (1990-1991) to produce the entire 1979-1992 record, the details of individual years seem to have been retained well. Nevertheless, the accuracy and the standard deviations of the TTOC observations are not yet well quantified because the ozone sondes did not provide an absolute reference due to the limited spatial and temporal coverage (Thompson and Hudson, 1999).

To illustrate possible effects, we calculated the values of $\epsilon_{1}$ and $\epsilon_{2}$ after applying a uniform negative 5 DU offset to the TTOC measurements. This brought model and measurements almost within one-sigma, and was an even more effective way to reduce the underestimate of TTOC than any of our sensitivity simulations. However, a 5 DU offset in TTOC cannot be justified, and the dependence of $\epsilon_{2}$ on the accuracy of the measured TTOC columns does not invalidate our approach. If the TTOC measurements change, for instance due to an update in the retrieval algorithm, $\epsilon_{2}$ can easily be re-defined to focus on regions that consequently appear most problematic, and then applied to the sensitivity runs to isolate possible solutions. Nevertheless, a thorough validation of the retrieved TTOC data using ozone sondes, as well as a more detailed quantification of the uncertainties would add to the usefulness of these data in global modeling studies.

The fact that a $5 \mathrm{DU}$ reduction in the observations would have greater impact than any of our sensitivity simulations further illustrates the robustness of ozone to perturbations. This is also obvious from the small ranges in $\epsilon_{1}$ and $\epsilon_{2}$ in Table 2. Although the change in boundary conditions is often quite extreme (factor of two), the response of ozone is only small. Table 3 illustrates that this nonlinear, damped response is mostly due to strong feedbacks in the $\mathrm{NO}_{\mathrm{x}}-\mathrm{HO}_{\mathrm{X}}$ chemistry, as well as in the deposition working against any change in the concentrations of ozone, $\mathrm{NO}_{\mathrm{x}}$, and $\mathrm{HNO}_{3}$. These feedbacks are especially important in the tropics, since both photochemistry and uptake of trace gases by vegetation depend strongly on the sunlight intensity. It is also the non-linearity of the system that requires CTMs to use sophisticated mathematical solvers for the chemistry with small 
time steps to solve the system of partial differential equations (PDE's), which generally consumes a large amount of computer resources.

An effective way to reduce the demand of computer resources is by pre-calculating the solution of the system of PDE's for many different boundary conditions and initial conditions. The solution of the system at each time step is then retrieved from an archive of solutions matching the forcing. Klonecki and Levy (1997) have shown that this can be done in a way that retains many of the feedbacks, and their model performs well in simulating tropical ozone, $\mathrm{CO}$ and $\mathrm{NO}_{\mathrm{x}}$. However, the interaction between $\mathrm{NO}_{\mathrm{x}}$ and $\mathrm{HO}_{\mathrm{x}}$ was not included in their simulations, which removes part of the nonlinear response of ozone. Therefore, the method of Klonecki and Levy (1997) produces more ozone over the tropical Atlantic and displays greater sensitivity to forcing (see also Galanter et al. (2000)). We speculate that the sensitivity of such models will usually be larger than in models that calculate the solution of the PDE's at each time step.

Our results show that the meteorology particularly strongly influences the distribution of ozone. It is striking that the range of values of $\epsilon_{1}$ in Fig. 5 is much larger than the range in Table 2. Apparently, zonal gradients in TTOC are largely determined by transport, and the location of lightning $\mathrm{NO}_{\mathrm{x}}$ emissions that are coupled to transport. Using actual meteorology has clear advantages over "climatological" meteorology, because the interannual variability is large, also addressed by Peters et al. (2001). Although the differences in correlation might seem quite low, we have shown that they are much greater than can be expected from random perturbations. The fact that improvements can be achieved indicates that the differences associated with transport are an important aspect of the models performance. Nevertheless, many models still rely on climatological wind fields, or apply one year of meteorological analyses to simulate any year of interest. This approach will yield results that are best compared to climatologies of observations, and are much less suited to study multi-year time series, or instantaneous distributions of species with lifetimes that are smaller than, or comparable to, the time scale of transport.

The requirements of the model concerning meteorology are very demanding. Not only does large scale transport determine the shape of the zonal TTOC distribution, meteorology also introduces interannual variability, and its interaction with biomass burning emissions is one of the most sensitive model parameters. However, meteorological conditions in the tropics are complex, and their representation in numerical weather prediction models such as the ECMWF model suffers from a lack of in-situ measurements that are used as constraints. Especially subgrid scale vertical mixing processes are difficult to model. This includes the vertical transport of biomass burning plumes. Mauzerall et al. (1998) estimated that the majority of ozone production takes place in these plumes. It thus seems obvious that besides improvements of our knowledge on the occurrence and intensity of fires, further improvements should focus on the sub-grid representation of turbulent and convective transport of biomass burning plumes, as well as the chemistry in these plumes.

Our study shows most convincingly that it is very unlikely that a single factor affecting ozone is responsible for the observed differences between model and observations. Given the serious disagreement, and the sensitivities as presented in Table 2, a combination of processes would be required to bring observations and model within one-sigma. This fact, together with the strongly damped response of ozone to the applied forcing strongly complicates attempts to infer information on model parameters (e.g. lightning $\mathrm{NO}_{\mathrm{x}}$ and biomass burning emissions) from the tropical distribution of TTOC. The simultaneous use of global $\mathrm{CO}$ and $\mathrm{NO}_{\mathrm{x}}$ observations, for instance, could be useful in this respect, as these could help to constrain the emissions. Ongoing developments in remote sensing might make these products available on spatial and temporal scales suitable for the approach presented in this work.

\section{Conclusions}

We have combined satellite observations of TTOC with model calculations to test the performance of our model and prioritize directions for improvement. Such a systematic comparison of model calculations with satellite observations has not been performed before, and it yields interesting insights in problems and possibilities associated with the use of increasingly available space-borne tropospheric observations. Through a large number of simulations, we were able to quantify the influence of meteorology, as well as biomass burning and lightning $\mathrm{NO}_{\mathrm{x}}$ emissions on the simulation of TTOC. Our most important conclusions are:

- With a standard set of emissions such as in Houweling et al. (1998); Lelieveld and Dentener (2000); Peters et al. (2001) the Atlantic TTOC maximum is not sufficiently captured, whereas the interannual variability over the Pacific Ocean is represented quite well.

- Using actual meteorology in a model is the most important prerequisite in reproducing the horizontal and vertical distribution of tropical tropospheric ozone.

- Efficient feedbacks in the tropical ozone budget strongly damp the response of ozone to changes in precursor emissions.

- Systematic improvements in our model can be achieved through a better representation of the biomass burning timing and magnitude, including their interannual variability. Further studies should focus on these processes, as well as the parameterization of lightning $\mathrm{NO}_{\mathrm{x}}$ emissions. 
- Quantitative use of satellite derived TTOC to test a global model is a promising approach, that would strongly profit from a more detailed quantification of the uncertainties in TTOC data.

Acknowledgements. We would like to thank Dr. Simon Pinnock of JRC for providing the fire counts and Rinus Scheele of the KNMI for his help in processing the ECMWF meteorological data. We also thank Dr. Jennifer Logan of Harvard University, and the National Oceanic and Atmospheric Administration (NOAA), the Climate Monitoring and Diagnostics Laboratory (CMDL), and the Carbon Cycle Group for making their data available through the internet. Finally, we thank the reviewers for their elaborate comments and helpful remarks.

\section{References}

Baray, J.-L., Daniel, V., Ancellet, G., and Legras, B.: Planetaryscale tropopause folds in the Southern subtropics, Geophys. Res. Lett., 27, 353-356, 2000.

Browell, E. V., Fenn, M.A., Butler, C.F., Grant, W.B., Clayton, M. B., Fishman, J., Bachmeier, A. S., Anderson, B. E., Fuelberg, H.E., Bradshaw, J.D., Sandholm, S. T., Blake, D. R., Heikes, B. G., Sachse, G. W., Singh, H. B., and Talbot, R. W.: Ozone and aerosol distributions and air mass characteristics over the South Atlantic basin during the burning season, J. Geophys. Res., 101, 24 043-24 068, 1996.

Burrows, J.P. and Chance, K. V.: SCIAMACHY and GOME: The scientific objectives, Optical Methods in Atmospheric Chemistry, 1715, 151-175, 1992.

Burrows, J.P., Richter, A., Wittrock, F., Eisinger, M., and Burrows, J. P.: The Global Ozone Monitoring Experiment (GOME): Mission Concept and First Scientific Results, J. Atmos. Sci., 56, 151-175, 1999.

Chance, K. V., Palmer, P., Spurr, R. J.D., Randall, M. V., Kurosu, T.P., and Jacob, D. J.: Satellite observations of formaldehyde over North America from GOME, Geophys. Res. Lett., 27, 3461-3464, 2000.

Chandra, S., Ziemke, J. R., Min, W., and Read, W. G.: Effects of 1997-1998 El Niño Southern Oscillation on tropospheric ozone and water vapor, Geophys. Res. Lett., 25, 3867-3870, 1998.

Cooke, W. F., Koffi, B., and Gregoire, J.-M.: Seasonality of vegetation fires in Africa from remote sensing data and application to a global chemistry model, J. Geophys. Res., 101, 21 051-21 065, 1996.

Craig, R.: The Upper Atmosphere: Meteorology and Physics, Academic, San Diego, Calif., 1965.

Crutzen, P. J., Tropospheric ozone: A review, in Tropospheric Ozone: Global and Regional Scale Interactions, edited by I. Isaksen, pp. 3-32, D. Reidel., Norwell-Mass., 1988.

Dentener, F. J. and Crutzen, P. J.: Reaction of $\mathrm{N}_{2} \mathrm{O}_{5}$ on tropospheric aerosols: Impact on the global distributions of $\mathrm{NO}_{x}, \mathrm{O}_{3}$, and $\mathrm{OH}$, J. Geophys. Res., 98, 7149-7163, 1993.

Dentener, F. J., Feichter, J., and Jeuken, A. B. M.: Simulation of transport of $\mathrm{Rn}^{222}$ using on-line and off-line global models at different horizontal resolutions: A detailed comparison with measurements, Tellus, 51B, 573-602, 1999.

Duncan, B.N. and Chameides, W.L.: Effects of urban emission control strategies on the export of ozone and ozone precursors from the urban atmosphere to the troposphere, J. Geophys. Res., 103, 28 159-29 179, 1998.

Dwyer, E., Pereira, M. C., Grégoire, J.-M., and DaCamara, C. C.: Characterization of the spatio-temporal patterns of global fire activity using satellite imagery for the period April 1992 to March 1993., Journal of Biogeography, 27, 57-69, 1999.

Eisinger, M. and Burrows, J. P.: Tropospheric sulfur dioxide observed by the ERS-2 GOME instrument, Geophys. Res. Lett., 25, 4177-4180, 1998.

Fishman, J. and Larsen, J. C.: Distribution of total ozone and stratospheric ozone in the tropics: Implications for the distribution of tropospheric ozone, J. Geophys. Res., 92, 6627-6634, 1987.

Galanter, M., Levy, H., and Carmichael, G. R.: Impacts of biomass burning on tropospheric $\mathrm{CO}, \mathrm{NO}_{x}$ and $\mathrm{O}_{3}$, J. Geophys. Res., 105, 6633-6653, 2000.

Ganzeveld, L. N., Lelieveld, J., and Roelofs, G. J.: A dry deposition parameterization for sulfur oxides in a chemistry-general circulation model, J. Geophys. Res., 103, 5679-5694, 1998.

Gery, M.W., Whitten, G.Z., Killus, J.P., and Dodge, M.C.: A photochemical kinetics mechanism for urban and regional scale computer modeling, J. Geophys. Res., 94, 12 925-12 956, 1989.

Gibson, R., Kallberg, P., and Uppsala, S.: The ECMWF re-analysis (ERA) project, ECMWF Newslett., 73, 7-11, 1997.

Guelle, W. Y., Balkanski, J., Schulz, M., Dulac, F., and Monfray, P.: Wet deposition in a global size-dependent aerosol transport model, 1 , Comparison of a 1 year ${ }^{210} \mathrm{~Pb}$ simulation with ground measurements, J. Geophys. Res., 103, 11 429-11 445, 1998.

Hao, W. M. and Liu, M.-H.: Spatial and temporal distribution of tropical biomass burning, Global Biogeochem. Cycles, 8, 495504, 1994.

Houweling, S., Dentener, F. J., and Lelieveld, J.: The impact of nonmethane hydrocarbon compounds on tropospheric photochemistry, J. Geophys. Res., 103, 10 673-10 696, 1998.

Houweling, S., Kaminski, T., Dentener, F. J., Lelieveld, J., and Heimann, M.: Inverse modeling of methane sources and sinks using the adjoint of a global transport model, J. Geophys. Res., 104, 26 137-26 160, 1999.

Hudson, R. D. and Thompson, A. M.: Tropical Tropospheric Ozone from Total Ozone Mapping Spectrometer by a modified residual method, J. Geophys. Res., 103, 22 129-22 145, 1998.

Jeuken, A. B. M.: Evaluation of chemistry and climate models using measurements and data assimilation, Ph.D. thesis, R. Dutch Meteorol. Inst. (KMNI), Utrecht, 2000.

Jeuken, A. B. M., Eskes, H. J., van Velthoven, P. F. J., Kelder, H. M., and Hölm, E. V.: Assimilation of total ozone satellite measurements in a three-dimensional tracer transport model, J. Geophys. Res., 104, 5551-5564, 1999.

Johnston, H. and Kinnison, D.: Methane photooxidation in the atmosphere: Contrast between two methods of analysis, J. Geophys. Res., 103, 21 967-21 984, 1998.

Kim, J.-H., Hudson, R. D., and Thompson, A. M.: A new method of deriving time-averaged tropospheric column ozone over the tropics using Total Ozone Mapping Spectrometer (TOMS) radiances: Intercomparison and analysis using TRACE-A data, J. Geophys. Res., 101, 24317-24330, 1996.

Klonecki, A. and Levy, H.: Tropospheric chemical ozone tendencies in a $\mathrm{CO}-\mathrm{CH}_{4}-\mathrm{NO}_{y}-\mathrm{H}_{2} \mathrm{O}$ system: Their sensitivity to variations in environmental parameters and their application to a global chemistry transport model study, J. Geophys. Res., 102, 21 221-21 238, 1997. 
Krishnamurti, T. N., Sinha, M., Kanamitsu, M., Oosterhof, D., Fuelberg, H., Chatfield, R., Jacob, D. J., and Logan, J. A.: Passive tracer transport relevant to the TRACE-A experiment, J. Geophys. Res., 101, 23 889-23 908, 1996.

Krol, M. C. and van Weele, M.: Implications of variations in photodissociation rates for global tropospheric chemistry, Atmos. Environ., 31, 1257-1273, 1997.

Landgraf, J. and Crutzen, P. J.: An efficient method for online calculation of photolysis and heating rates, J. Atmos. Sci., 55, 863878,1998

Lelieveld, J. and Dentener, F. J.: What controls tropospheric ozone?, J. Geophys. Res., 105, 3531-3551, 2000.

Levy, H., Moxim, W.J., and Kasibhatla, P. S.: A global threedimensional time-dependent lightning source of tropospheric $\mathrm{NO}_{x}$, J. Geophys. Res., 101, 22 911-22 922, 1996.

Logan, J. A.: An analysis of ozonesonde data for the troposphere: Recommendations for testing 3-D models and development of a gridded climatology for tropospheric ozone, J. Geophys. Res., 104, 16 115-16 149, 1999.

Louis, J. F.: A parametric model of vertical eddy fluxes in the atmosphere, Boundary Layer Meteorol., 17, 178-202, 1979.

Mackerras, D. and Darveniza, M.: Latitudinal variation of lightning occurrence characteristics, J. Geophys. Res., 99, 10 813-10 822, 1994.

Martin, R. V., Jacob, D. J., Logan, J. A., Ziemke, J. R., and Washington, R.: Detection of a lightning influence on tropical tropospheric ozone, Geophys. Res. Lett., 27, 1639-1642, 2000.

Marufu, L., Dentener, F. J., Lelieveld, J., Andreae, M. O., and Helas, G.: Photochemistry of the African troposphere: The influence of biomass burning emissions, J. Geophys. Res., 105, 14513 $14540,2000$.

Mauzerall, D. L., Logan, J., Jacob, D. J., Anderson, B.E., Brune, Blake, D. R., Talbot, B., Bradshaw, J. D., Heikes, B., and Sachse, G. W.: Photochemistry in biomass burning plumes and implications for tropospheric ozone over the tropical South Atlantic, J. Geophys. Res., 103, 8401-8423, 1998.

McPeters, R. D. and Labow, G. J.: An assessment of the accuracy of 14.5 years of Nimbus TOMS Version 7 ozone data by comparison with the Dobson network, Geophys. Res. Lett., 23, 36953698, 1996.

Meijer, E. W., van Velthoven, P. F. J., Brunner, D. W., Huntrieser, H., and Kelder., H. M.: Improvement and evaluation of the parameterisation of nitrogen oxide production by lightning, Phys. Chem. of the Earth, 557-583, 2001.

Olivier, J., Bouwman, A., v. d. Maas, W., Berdowski, J., Veldt, C., Bloos, J., Visschedijk, A., and Haverlag, J.: Description of EDGAR version 2.0, Rijks-inst. voor Volksgezondheid en Milieu, Bilthoven, Rep. 771060002, 1996.

Pan, L., Gille, J.C., Edwards, D. P., Bailey, P.L., and Rodgers, C. D.: Retrieval of tropospheric carbon monoxide for the MOPITT experiment, J. Geophys. Res., 103, 32 277-32 290, 1998.

Peters, W., Krol, M. C., Dentener, F. J., and Lelieveld, J.: Identification of an El Niño-Southern Oscillation signal in a multiyear global simulation of tropospheric ozone, J. Geophys. Res., 106, 10 430-10 444, 2001.

Pickering, K. E., Wang, Y., Tao, W. K., Price, C., and Müller, J. F.: Vertical distributions of lightning $\mathrm{NO}_{x}$ for use in regional and global chemical transport models, J. Geophys. Res., 103, 31203 $31216,1998$.

Pinty, B., Roveda, F., Verstraete, M. M., Gobron, N., Govaerts, Y.,
Martonchik, J. V., Diner, D. J., and Kahn, R. A.: Surface albedo retrieval from Meteosat, 2. Applications, J. Geophys. Res., 105, $18114-18134,2000$

Pöschl, U., Lawrence, M. G., von Kuhlmann, R., and Crutzen, P. J.: Comment on: "Methane photooxidation in the atmosphere: Contrast between two methods of analysis" by Harold Johnston and Douglas Kinnison., J. Geophys. Res., 105, 1431-1432, 2000.

Pöschl, U., von Kuhlmann, R., Poisson, N., and Crutzen, P. J.: Development and Intercomparison of Condensed Isoprene Oxidation Mechanisms for Global Modeling, J. Atm. Chem., 37, 2952, 2000.

Prather, M., Ehhalt, D., Dentener, F. J., Derwent, R., Dlugokencky, E., Holland, E., Isaksen, I., Katima, J., Kirchhoff, V., Matson, P., Midgley, P., and Wang, M.: Atmospheric Chemistry and Greenhouse gases, in Climate Change 2001: Contribution of Working group I to the Third assessment report of the Intergovernmental Panel on Climate Change., edited by J.Houghton et al., p. 881, Cambridge University press,Cambridge and New York, NY, USA, 2001.

Price, C. and Rind, D.: A simple lightning parameterization for calculating lightning distributions, J. Geophys. Res., 97, 99199933, 1992.

Richter, A., Wittrock, F., Eisinger, M., and Burrows, J. P.: GOME observations of tropospheric $\mathrm{BrO}$ in Northern Hemispheric spring and summer 1997, Geophys. Res. Lett., 25, 2683-2686, 1998.

Russel, G. and Lerner, J.: A new finite-differencing scheme for the tracer transport equation, J. Appl. Meteorol., 20, 1483-1498, 1981

Singh, H. B., Kanakidou, M., Crutzen, P. J., and Jacob, D. J.: High concentrations and photochemical fate of oxygenated hydrocarbons in the global atmosphere, Nature, 378, 50-54, 1995.

Thompson, A. M. and Hudson, R. D.: Tropical tropospheric ozone (TTO) maps from Nimbus 7 and Earth Probe TOMS by the modified-residual method: Evaluation with sondes, ENSO signals, and trends from Atlantic regional time series, J. Geophys. Res., 104, 26 961-26 975, 1999.

Thompson, A. M., Pickering, K.E., McNamara, D. P., Schoeberl, M.R., Hudson, R.D., Kim, J.H., Browell, E. V., Kirchhoff, V. W. J.H., and Nganga, D.: Where did tropospheric ozone over Southern Africa and the tropical Atlantic come from in October 1992? Insights from TOMS, GTE/TRACE-A, and SAFARI-92, J. Geophys. Res., 101, 24 251-24 278, 1996.

Thompson, A. M., Doddridge, B. G., Witte, J. C., Hudson, R. D., Luke, W. T., Johnson, J.E., Johnson, B. J., Oltmans, S. J., and Weller, R.: A tropical Atlantic ozone paradox: Shipboard and satellite views of a tropospheric ozone maximum and wave-one in January-February 1999, Geophys. Res. Lett., 27, 3317-3320, 2000.

Thompson, A. M., Witte, J.C., Hudson, R. D., Guo, H., Herman, J.R., and Fujiwara, M.: Tropical Tropospheric Ozone and Biomass Burning, Science, 291, 2128-2132, 2001.

Thompson, A. M., Witte, J.C., McPeters, R.D., Oltmans, S. J., Schmidlin, F. J., Logan, J. A., Fujiwara, M., Kirchhoff, V. W. J. H., Posny, F., Coetzee, G. J. R., Hoegger, B., Kawakami, S., Ogawa, T., Johnson, B.J., Vmel, H., and Labow, G. The 1998-2000 SHADOZ (Southern Hemisphere ADditional OZonesondes) tropical ozone Climatology. 1. Comparison with TOMS and ground-based measurements, J. Geophys. Res. (in press), 2002 
Tiedtke, M. A.: A comprehensive mass flux scheme for cumulus parameterization in large-scale models, Mon. Weather Rev., 117, 1779-1800, 1989.

Wesely, M. L.: Parameterization of surface resistance to gaseous dry deposition in regional-scale numerical models, Atmos. Environ., 23, 1293-1304, 1989.

Yienger, J. J. and Levy, H.: Global inventory of soil-biogenic $\mathrm{NO}_{x}$ emissions, J. Geophys. Res., 100, 11 447-11 464, 1995.
Ziemke, J. R., Chandra, S., and Bhartia, P.-K.: Two new methods for deriving tropospheric column ozone from TOMS measurements: The assimilated UARS MLS/HALOE and convective-cloud differential techniques, J. Geophys. Res., 103, 22 115-22 128, 1998.

Ziemke, J.R., Chandra, S., and Bhartia, P.-K.: Seasonal and interannual variabilities in tropical tropospheric ozone, J. Geophys. Res., 104, 21 245-21 442, 1999. 